\title{
FATTY ACIDS AS BIOCOMPOUNDS: THEIR ROLE IN HUMAN METABOLISM, HEALTH AND DISEASE - A REVIEW. PART 2: FATTY ACID PHYSIOLOGICAL ROLES AND APPLICATIONS IN HUMAN HEALTH AND DISEASE
}

\author{
Lefkothea-Stella Kremmyda, Eva Tvrzicka*, Barbora Stankova, Ales Zak
}

\author{
Charles University in Prague, $1^{\text {st }}$ Faculty of Medicine, $4^{\text {th }}$ Department of Medicine, Czech Republic \\ E-mail: eva.tvrzicka@lfl.cuni.cz
}

Received: April 13, 2011; Accepted with revision: October 4, 2011

Key words: Fatty acids/Lipid mediators/Gene expression/Development/Cardiovascular/Cancer/Immunity

Background. This is the second of two review parts aiming at describing the major physiological roles of fatty acids, as well as their applications in specific conditions related to human health.

Results. The review included the current literature published in Pubmed up to March 2011. In humans, fatty acids are a principle energy substrate and structural components of cell membranes (phospholipids) and second messengers. Fatty acids are also ligands of nuclear receptors affecting gene expression. Longer-chain (LC) polyunsaturated fatty acids (PUFA), including eicosapentaenoic acid (EPA), docosahexaenoic acid (DHA), and arachidonic acid are precursors of lipid mediators such as eicosanoids (prostaglandins, leukotrienes, thromboxanes), resolvins and neuroprotectins. Lipid mediators produced by EPA and DHA (LC n-3 PUFA; mainly found in oily fish) are considered as inflammation-resolving, and thus, fish oil has been characterised as antiinflammatory. Recommendations for EPA plus DHA intake from oily fish vary between $250-450 \mathrm{mg} /$ day. Dietary reference values for fat vary between nutrition bodies, but mainly agree on a low total and saturated fat intake. The existing literature supports the protective effects of LC n-3 PUFA (as opposed to n-6 PUFA and saturated fat) in maternal and offspring health, cardiovascular health, insulin sensitivity, the metabolic syndrome, cancer, critically ill patients, and immune system disorders.

Conclusion. Fatty acids are involved in multiple pathways and play a major role in health. Further investigation and a nutrigenomics approach to the effects of these biocompounds on health and disease development are imperative and highlight the importance of environmental modifications on disease outcome.

\section{INTRODUCTION}

Fatty acid (FA) intake in the form of dietary fat has increased over the past forty years with the introduction of a more westernised lifestyle ${ }^{1,2}$. This dietary modification reflects also changes in the type of fat consumed towards increased consumption of saturated animal fat and lower intake of unsaturated fat (plant and marine sources) (ref. ${ }^{3}$ ). These dietary changes, along with others including decreased intake of antioxidants, vitamins, and minerals, in combination with environmental and lifestyle changes (pollutants, smoking, decreased physical activity levels), may play a detrimental role in human physiology, altering health and disease outcomes.,

This review consists of two parts. Regarding biosynthesis, dietary sources, biological roles of fatty acids and lipid classes please refer to Part 1 of this review ${ }^{4}$. Fatty acids can be desaturated endogenously up to the $\Delta 9$ position due to lack of certain enzymes in humans. For this reason linoleic (LA; 18:2n-6) and $\alpha$-linolenic (ALA; 18:3n-3) acids must be taken from the diet and are termed essential FA (EFA). Further elongation and desaturation of these FA to produce long-chain (LC) polyunsaturated FA (PUFA), including eicosapentaenoic (EPA; 20:5n-3), docosahexaenoic (DHA; 22:6n-3) and arachidonic acids (AA; 20:4n-6), is possible but not very efficient in humans. Thus, these FA may be characterised as conditionally essential depending on EFA availability. Genetic variation in human desaturase genes affects FA metabolism, plasma lipid profiles, and risk of disease development ${ }^{5-7}$. Recommendations for minimum dietary intake of EPA plus DHA vary between $250-450 \mathrm{mg} / \mathrm{day}^{8}$, especially for pregnant women and those of reproductive age. Rich sources of LC n-3 PUFA are fish oils and the flesh of oily fish, whereas non-oily (white) fish contain them but in lower amounts.

Long-chain PUFA with 18-20 carbon atoms, including EPA and AA, are precursors of eicosanoids (prostaglandins, leucotrienes and thromboxanes), which have a broad scale of regulatory, autocrine and paracrine effects. Long-chain PUFA with 20 and 22 carbon atoms are precursors of autacoids - resolvins (resolution phase interaction products), lipoxins and neuroprotectins ${ }^{9}$. FA are also ligands of nuclear receptors which take part in the subcellular control of metabolic pathways. Covalent modification of proteins by FA acylation enables their incorporation into membranes. Hydroxy FA are activators of some nuclear factors and are responsible for the expression of proinflammatory cytokines (interleukin (IL)-1, IL-6, IL-8, tumour necrosis factor (TNF)- $\alpha$ ) and adhesion molecules (intercellular adhesion molecule (ICAM)-I, vascular cell adhesion molecule (VCAM)-I). 
These actions of FA and the lipid mediators produced exhibit the significance of FA for human metabolism and are reviewed in the present (second) part of this review. Various studies from current literature highlighting the physiological roles of FA and practical implications for health and disease, including maternal and offspring health, growth and development, EFA deficiency, oxidative stress, cardiovascular health, the metabolic syndrome, cancer, critically ill patients, and immune system disorders will be discussed here.

\section{PHYSIOLOGICAL ROLES OF FATTY ACIDS}

In humans, FA have a number of physiological roles as: energy substrates, structural and functional components of cell membranes, precursors for lipid mediators, components affecting signal transduction pathways and gene transcription. These roles will be presented in the following paragraphs.

\section{Fatty acids as energy substrates}

Fatty acids in the form of triacylglycerols (TAG) from dietary fat are a principal source of energy. Compared to proteins and carbohydrates they have about twice as much energy value and their storage in adipose tissue needs less amount of water. Around $25-35 \%$ of total energy intake (TEI) in humans comes from dietary fat, which is equivalent to an intake of 56-78 $\mathrm{g}$ of fat per day for a standard $8400 \mathrm{~kJ}$ (2000 kcal) diet. However, as fat intake has increased within recent years in western-type environments, this amount can be as high as $40-45 \%$ of TEI depending on food sources and habitual consumption. The energy value of LC FAs and very long chain FA (VLCFA) is $38 \mathrm{~kJ} / \mathrm{g}(9 \mathrm{kcal} / \mathrm{g})$, and that of medium chain FAs is $29 \mathrm{~kJ} / \mathrm{g}(7 \mathrm{kcal} / \mathrm{g})$. Short chain FAs represent an energy source for enterocytes and colonocytes. Fatty acids take part in transferring and depositing important lipid soluble molecules (such as vitamins A, D, E and K) and are precursors of lipid mediators (discussed below). Therefore, nutritional recommendations have been established regarding total fat and different types of fat, including EFA and LC n-3 PUFA. These will be presented below under the section entitled 'Fatty acids in health and disease'.

\section{Structural role of fatty acids}

\section{a. Isolators}

Tissues with high content of TAG, such as subcutaneous and visceral fat, serve as temperature (e.g. in marine mammals like seals) and mechanical isolators. Moreover, VLCFA are structural components of ceramides, which decrease skin permeability to water and prevent its loss$\mathrm{es}^{10}$. A characteristic example is the presence of VLCFA in secretions of the Meibomian glands, where they serve as a barrier between tear film and skin lipids, preventing excessive evaporation of tears. Neural tissues contain insulating lipids which cover the neurones. The thicker the myelin layer, the faster the signal conduction along the axon.

\section{b. Cell membrane structure}

Fatty acids in the form of phospholipids are the structural components of all cell membranes. Their profile influences the thickness and fluidity of the membrane and, thus, the activity of membrane associated proteins (enzymes, ion channels, receptors and transporters) $\left(\right.$ ref. $\left.{ }^{10}\right)$. Phospholipid molecules include a hydrophilic 'head' (choline, ethanolamine, serine, inositol) connected through phosphoric acid to a hydrophobic part (one or two FA molecules). This enables the special arrangement of the lipid bilayer which incorporates hydrophobic molecules on the inner part of the membrane, and hydrophilic molecules on the outer part. Membrane stability is increased by the presence of specific molecules, such as cholesterol and specific proteins; the higher the content of these molecules, the lower the membrane fluidity. An additional factor that influences membrane fluidity is the degree of FA unsaturation. Unsaturated membrane FAs mainly have double bonds in cis configuration and each double bond results in approximately $60^{\circ}$ folding of the hydrocarbon chain. As a result, FA chains occupy greater space which increases membrane fluidity. In contrast, saturated FAs (SFA) or unsaturated FAs in trans configuration, whose chains are straight and take up less space, decrease membrane fluidity. Notably, increasing the degree of unsaturation for a given phospholipid content influences membrane fluidity less than increasing phospholipid content itself (e.g. phospholipid : cholesterol or phospholipid : proteins ratio) (ref. ${ }^{10}$ ).

The lipoprotein cover has a similar structure to the cell membrane. It also contains phospholipids, cholesterol, and specific proteins which are called apolipoproteins. The polar heads of phospholipids are orientated toward the surface of lipoproteins and this enables lipoprotein solubility in plasma. The hydrophobic FA chains are orientated toward the core of the particle which is composed of cholesteryl esters (CE) and TAG. Lipoprotein membrane fluidity increases in the following order: high density lipoproteins (HDL) < low density lipoproteins $(\mathrm{LDL})<$ very low density lipoproteins (VLDL) (ref. $\left.{ }^{11}\right)$.

\section{c. Second messenger chemical structure}

Phosphatidylinositol (PI) and phosphatidylcholine (PC) may act as sources of intracellular signals in response to extracellular signals which interact with receptors on the outer layer of plasma membrane. Hormones, or other extracellular signals, bind to the plasma membrane receptor which leads to activation of phospholipase (PL) C (ref. ${ }^{12}$ ). Phospholipase C hydrolyses PI 4,5-bisphosphate (PIP2) releasing inositol 1,4,5-triphosphate (IP3) and diacylglycerol (DG). In consequence, IP3 (which is water soluble) causes release of calcium $\left(\mathrm{Ca}^{2+}\right)$ from the endoplasmic reticulum. The combination of DG (which is lipid soluble and stays bound to the plasma membrane) and increased levels of $\mathrm{Ca}^{2+}$ lead to activation of the enzyme protein kinase $\mathrm{C}(\mathrm{PKC})$. This enzyme catalyses the phosphorylation of some cellular proteins, affecting cellular responses to the initial extracellular trigger (hormone) $\left(\right.$ ref..$\left.^{10}\right)$. Fatty acids originating from the sn-2 glycerol carbon of PC influence the activity of sec- 


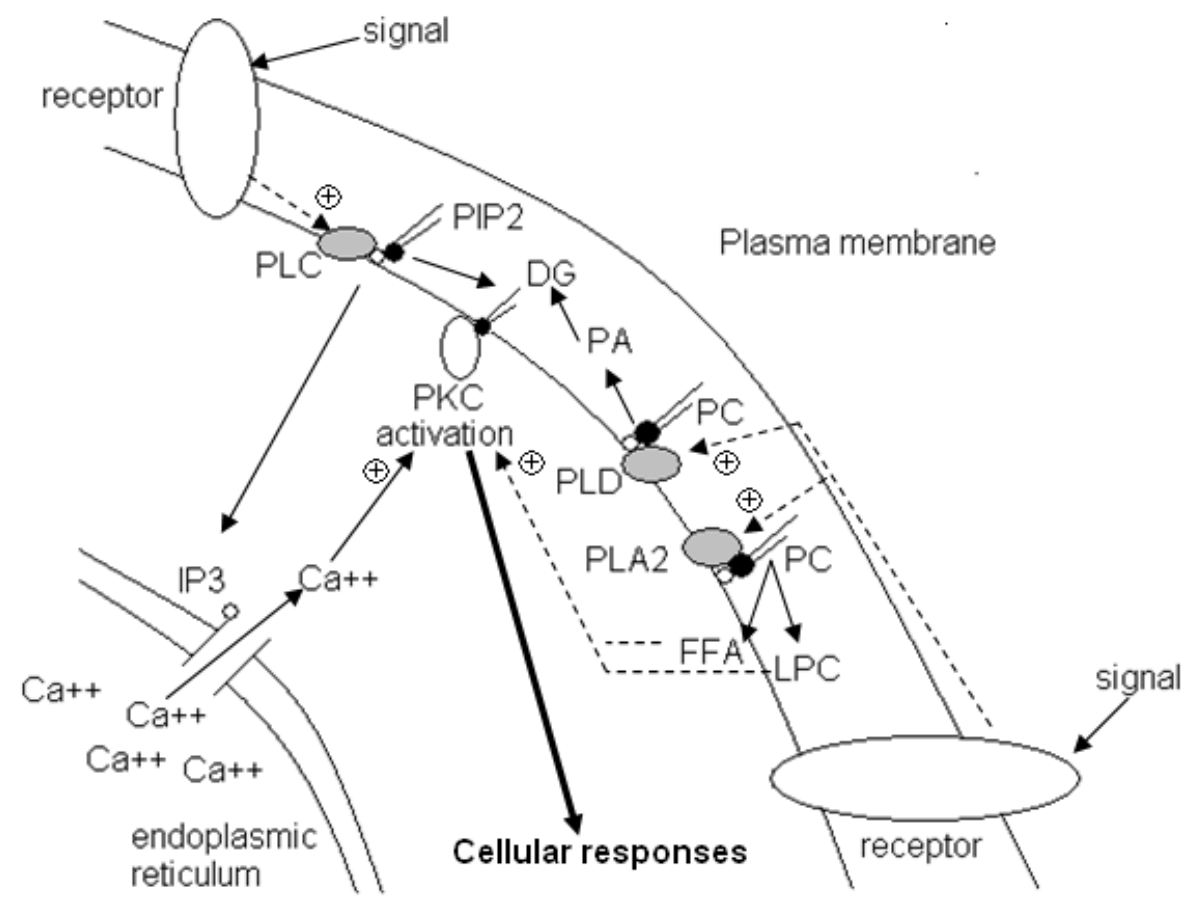

Fig. 1. Lipids as second messengers regulating metabolism.

$\mathrm{Ca}^{++}$, Calcium; DG, Diacylglycerol; FFA, Free fatty acid; IP3, Inositol 1,4,5-triphosphate; LPC, Lyso-phosphatidylcholine; PA, Phosphatidic acid; PC, Phosphatidylcholine; PI, Phosphatidylinositol; PL, Phospholipase; PIP2, Phosphatidylinositol 4,5-bisphosphate; PKC, Protein kinase C.

ond messengers (DG), as schematically shown in (Fig. 1). An extracellular signal binds with a plasma membrane receptor which in turn activates the enzymes PLD and PLA2. This results in production of phosphatidic acid (PA), though the enzymatic action of PLD on PC, which is later metabolised to DG. This leads to PKC activation. PC is also hydrolysed by PLA2 to free FA (FFA) and lysoPC (LPC) which can potentially promote PKC activation and influence cellular responses ${ }^{13}$.

\section{Fatty acids as precursors of lipid mediators}

Fatty acids of the cell membrane are precursors of lipid mediators, with eicosanoids (prostaglandins, PG; thromboxanes, TX; leukotrienes, LT) being one of the most important ${ }^{14}$. They are called eicosanoids because they are formed by 'precursor' FA which contain 20 carbon atoms (from the Greek "eikosi" = twenty). Specifically, PUFA derived from the sn-2 glycerol carbon of cell membrane phospholipids, namely AA and EPA, are precursors of a number of eicosanoids. Other FAs such as DHA, docosapentaenoic acid (DPA; 22:5n-3), LA and Mead acid (20:3n-9) are precursors of various other lipid mediators as shown in (Table 1). Prostaglandin and TX synthetases, enzymes which catalyze the first step in a pathway leading through endoperoxides (PGG2 and PGH2) to prostacycline, PG, and TX, consist of a cyclooxygenase (COX) and a hydroperoxidase. Fatty acids are released from the cell membrane with the aid of PLA2 and transformed by COX type 1 and 2 to PG and TX, by lipoxygenase (LOX) type 5, 8, 12 and 15 to LT, hydrox- yeicosatetraenoic (HETE), hydroperoxyeicosatetraenoic (HPETE), and hydroxyeicosapentaenoic (HEPE) acids. Also, recently found are trihydroxy-derivatives of EPA which are termed E-series resolvins (Rv) or lipoxins (LX), as well as dihydroxy- and trihydroxy-derivatives of DHA including D-series Rv (ref. ${ }^{15,16}$ ), protectins (docosatrienes) or neuroprotectins (NP) (ref. ${ }^{17,18}$ ), and maresins (MaR). These have been termed specialised pro-resolving mediators (SPM) since they are involved in the clearance and regulation of inflammatory substances ${ }^{19,20}$. Numbers in the PG and TX shorthand notation represent the number of double bonds in the molecule; the double bonds can be used for formation of cyclic- or oxy-derivatives.

Eicosanoids are rudimentary hormones or regulating molecules that appear in most organisms. Unlike endocrine hormones, which travel in the blood stream, eicosanoids have autocrine or paracrine actions. They alter the activity of the cells from which they were synthesised and of adjoining cells by binding to 7-transmembrane- helix (7-TM) receptors. Prostaglandins stimulate inflammation, regulate blood flow to particular organs, control ion transport across membranes, and modulate synaptic transmission. Thromboxanes are vasoconstrictors and potent hypertensive agents which also facilitate platelet aggregation. They are named after their role in clot formation (thrombosis). Thromboxane A2, produced by activated platelets, has prothrombotic properties, stimulating activation of new platelets as well as platelet aggregation. Lipoxygenase catalyses the initial step of the pathway leading to LT. Their name reflects the fact that they were 


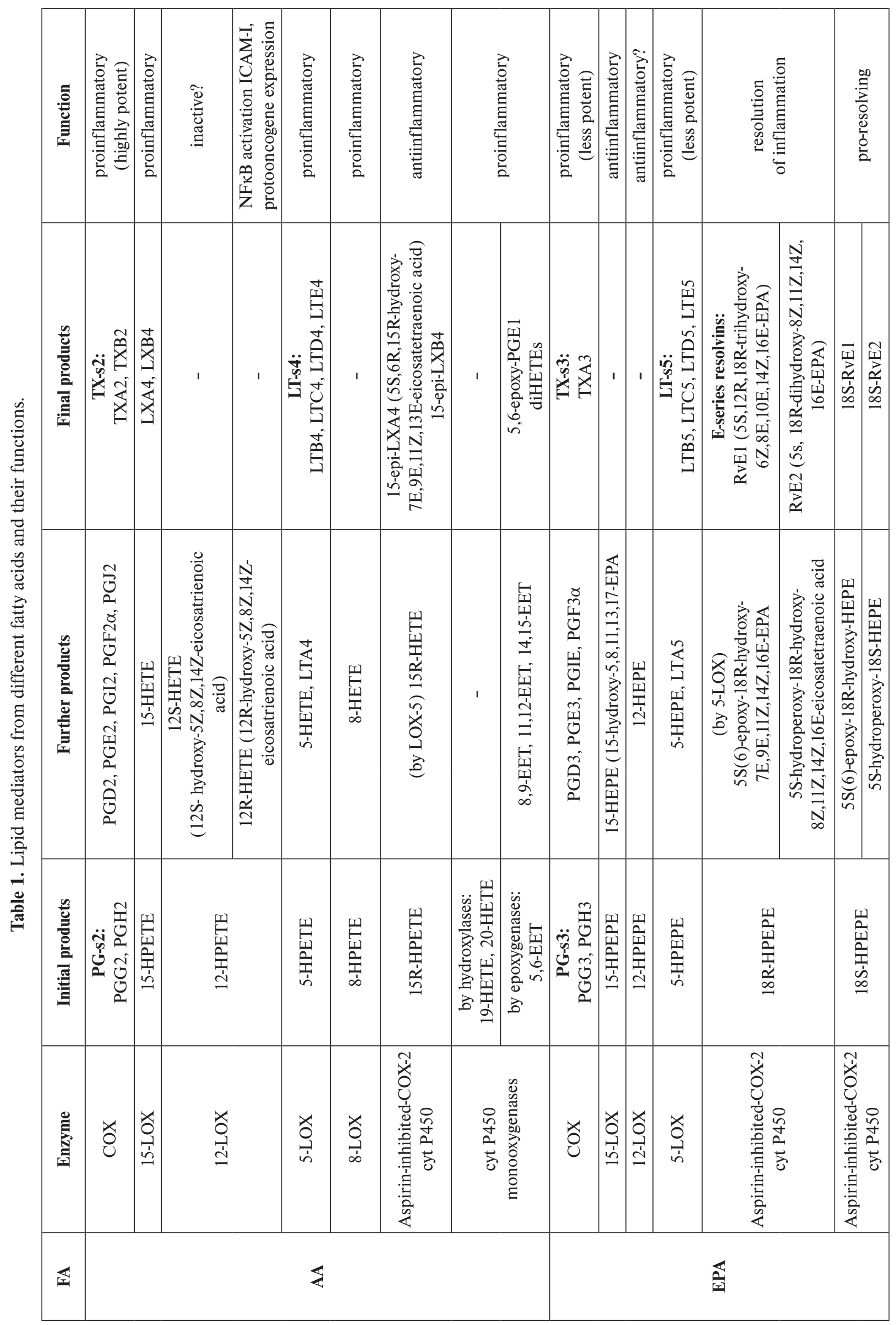


Fatty acids as biocompounds: their role in human metabolism, health and disease - a review.

Part 2: fatty acid physiological roles and applications in human health and disease

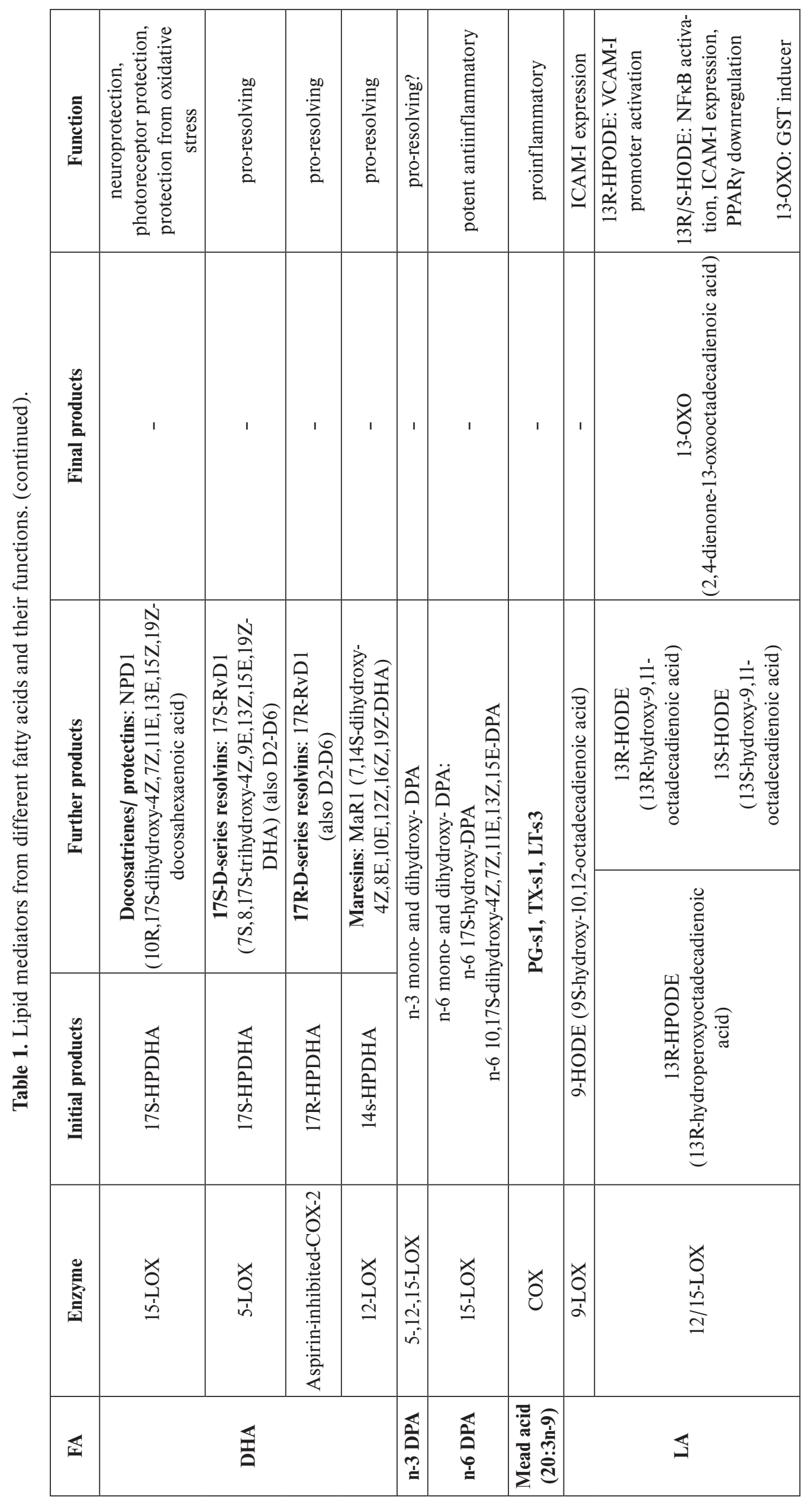

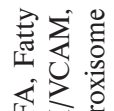

不

可

亩. 응

휴휴

议

항

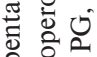

语昰

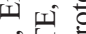

商

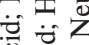

恶

范

莺芯

㱐

空

空

舁它号

㦴密

난

矛产家

可

嗐 。

:

㝴营

额

这

응 항

要空

证

这塄

0 苛

通

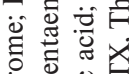

㐘

U. 궁

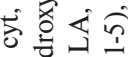

通全的

동

方武

응 可

苮

윰

递

号焉总

战 
first found in leukocytes and contain three conjugated double bonds ${ }^{14}$.

Acetylsalicylic acid (Aspirin), an antiinflammatory and antithrombotic drug, as well as other non-steroidal antiinflammatory drugs (NSAID), irreversibly stop the synthesis of eicosanoids, thus affecting many signalling pathways. Stopping eicosanoid synthesis results in the wide-range effects that NSAID have on inflammation, fever, pain, and blood clotting. An endogenous eicosanoid called anandamide (arachidonylethanolamide) can specifically bind to cannabinoid receptors (CB); CB1 is expressed in the brain, gastrointestinal tract and adipose tissue, whereas CB2 is expressed in cells of the immune system ${ }^{21}$.

The effect of lipid mediators produced is very much dependent on their FA substrate. Different eicosanoids are produced from AA and EPA and these have different, often opposing, actions ${ }^{22}$. Arachidonic acid is the precursor of 2-series PG and 4-series LT, whereas EPA is the precursor of 3-series PG and 5-series LT. The AAderived PG and LT are synthesised in response to injury or stress, whereas the EPA-derived PG and LT appear to modulate the effects of 2-series PG and 4-series LT (usually on the same target cells). Eicosapentaenoic acidderived $\mathrm{PG}$ is formed at a slower rate and attenuates the effects of excessive levels of AA-derived PG. Adequate production of these seems to protect against heart attack and stroke as well as certain inflammatory diseases such as arthritis, lupus, and asthma ${ }^{23}$. The suppression of $n-6$ PUFA-derived eicosanoid production by n-3 PUFA may be caused by their competition for a common enzyme in the eicosanoid biosynthetic pathway, $\Delta 6$-desaturase. Also, EPA, through its mono- and trihydroxy-derivatives, decreases the production of proinflammatory cytokines (e.g. IL-1 $\beta$, TNF- $\alpha$ ). Consequently, EPA-derived eicosanoids are considered to be less inflammatory potent than those derived from AA, and this is one of the main reasons that fish oil (containing EPA but also DHA) has been characterised as having antiinflammatory properties ${ }^{24,25}$.

\section{Fatty acids and lipoperoxidation}

Spontaneous reactions of the FA chain with molecular oxygen are studied because of the possible involvement of reaction products in destructive biological processes. Auto-oxidative processes result in a number of compounds (e.g. hydroperoxides). Fatty acids with two or more double bonds give rise to cyclic products. These compounds are not stable and, through hydroxyderivates, they form stable compounds with carbonyl groups. Some of these compounds are used as markers of oxidative stress ${ }^{26}$.

Linoleic acid, EPA, Mead acid (20:3n-9) and DHA may be substrates for lipoperoxidation. Specific markers of LA lipoperoxidation are 9- and 13-hydroxyoctadecanoic acids (9-HODE and 13-HODE), 2,4-dienone 13-oxooctadeca-9,11-dienoic acid (13-OXO) and 13-hydroperoxyoctadecanoic acid (13-HPODE). The latter is a significant component of oxidised LDL cholesterol and a more potent activator of nuclear factor kappa $\mathrm{B}(\mathrm{NF} \mathrm{B})$ than 13-HODE.
Products of non-enzymatic oxidation of AA and other 20 carbon atom FA (isoprostanes) are used as surrogate markers of oxidative stress. Other cyclic products are formed from ALA, EPA and DHA, so-called neuroprostanes. The formation of non-cyclic structures termed isoketals has been also described ${ }^{27}$.

\section{Fatty acid role in protein acylation}

Acylation of proteins is an important covalent modification of proteins. It enables them to become incorporated into biological membranes and thus increase their structural stability, protein-to-protein interactions, as well as their catalytic activity ${ }^{28}$. Modified proteins fulfill a number of functions in the organism. There are two pathways of protein acylation:

1) co-translational irreversible acylation catalysed by $\mathrm{N}$-myristoyl transferase, and

2) post-translational reversible thioesterification of cysteine, which is not directly related to protein production and is important even in cells without transcriptional activities (e.g. platelets) $\left(\right.$ ref. $\left.^{28}\right)$.

Supplementation with n-3 PUFA favourably influences acylation of proteins and functions of ion-channels in the myocardium improving electrical stability. It reduces the risk of sudden cardiac death as well as fatal myocardial infarction (DART Study, Lyon Heart Study and GISSI Prevenzione Trial) (ref. ${ }^{29-31}$ ).

Fatty acid role in signal transduction and gene transcription pathways

\section{a. Modulators of gene transcription}

Cell signalling ensures transfer of information between cells and disorder of cell signalling may be involved in disease pathogenesis. Signal pathways can be influenced by genes, nuclear factors and receptors. Fatty acids as ligands of these receptors or as modulators of gene transcription can significantly influence cell signalling ${ }^{32}$. Long chain unsaturated FA (C20-22) and their metabolites have been identified as effective ligands of nuclear receptors of some transcription factors:

1) peroxisome proliferator-activated receptor (PPAR) $-\alpha$, $-\beta / \delta,-\gamma 1$ and $-\gamma 2$

2) liver $X$ receptors (LXR) type $\alpha$ and $\beta$

3) hepatic nuclear factor (HNF) $4 \alpha$

4) sterol regulatory element binding protein (SREBP) -1 and -2 .

5) carbohydrate regulatory element binding protein/Maxlike factor X (ChREBP/MLX) (ref. ${ }^{33,34}$ ).

Dietary fat regulates the above transcription factors associated with hepatic glycolysis, fatty acid synthesis and oxidation. These transcription factors have various roles: SREBP-1 upregulates the activity of enzymes involved in FA synthesis (including PUFA), desaturation and elongation; ChREBP/MLX upregulates de-novo lipogenesis and MFA synthesis (but not PUFA synthesis), and induces glucose transporter-2 and L-pyruvate kinase involved in 


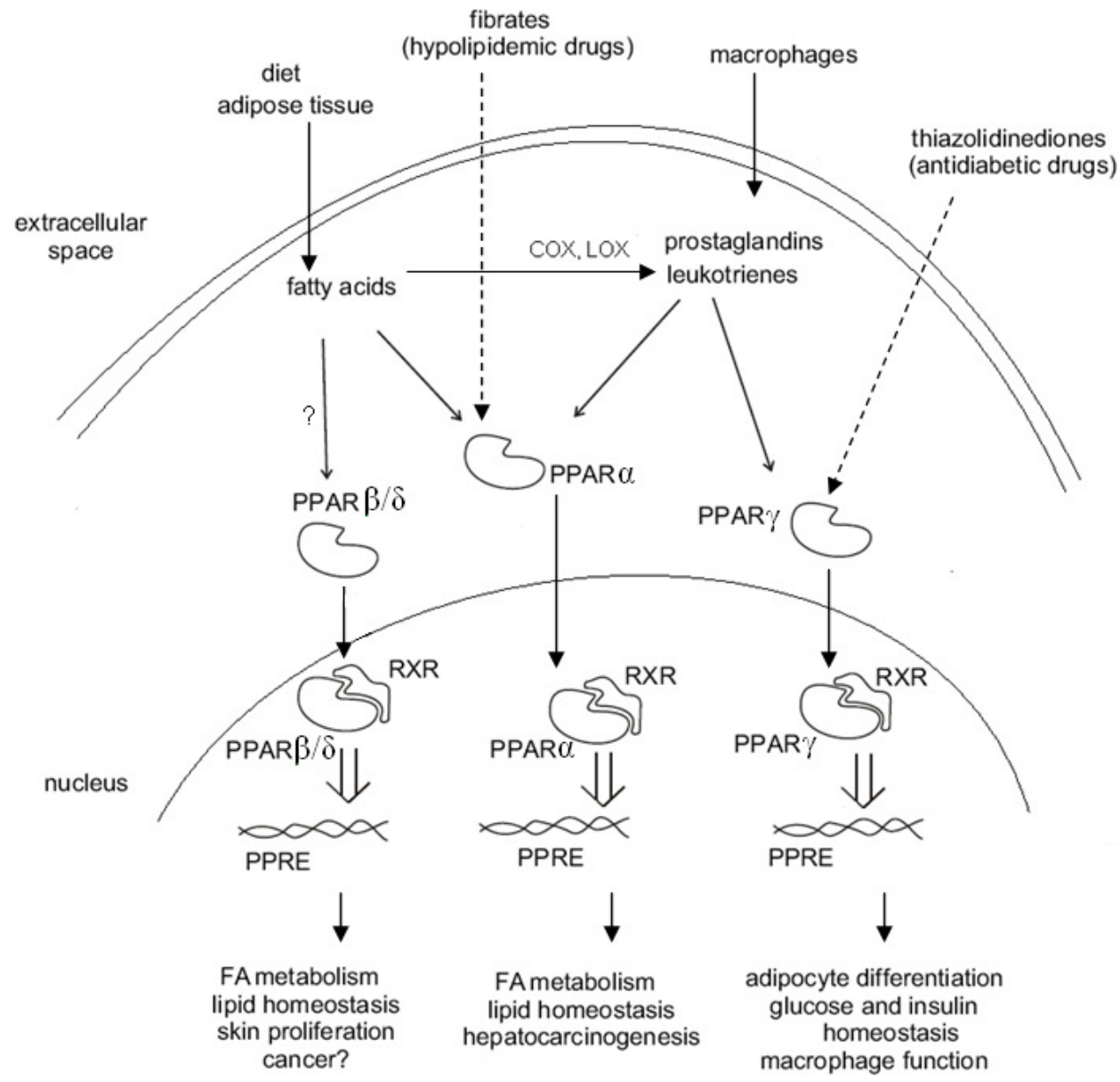

Fig. 2. Mechanism of action of peroxisome proliferator-activated receptors.

COX, Cyclooxygenase; LOX, Lipoxygenase; PPAR, Peroxisome proliferatoractivated receptor; PPRE, Peroxisome proriferator-response element; RXR, Retinoid X receptor.

glucose metabolism; PPAR- $\alpha$ induces mainly PUFA synthesis and FA oxidation; LXR induces de-novo lipogenesis and MFA synthesis ${ }^{33,34}$.

Long chain n-3 PUFA promote (as ligands) PPAR and inhibit LXR. The mechanism of PPAR action is shown in (Fig. 2). As shown, PPAR can be activated by FA (LC n-3 PUFA), eicosanoids and different drugs (fibrates, thiazolidinediones). They act through dimerisation with retinoid-X-receptor (RXR) in the nucleus ${ }^{35}$. The transcription factors interact with peroxisome proliferator-response elements (PPRE) in DNA encoding proteins involved in many important metabolic pathways (lipid and glucose homeostasis, hepatocarcinogenesis, adipose tissue homeostasis etc.) (ref. $\left.{ }^{36}\right)$.

Feedback regulation of $\mathrm{HNF}-4 \alpha$ is performed by thioesters of acyl-coenzyme A of PUFA. Furthermore, SREBP, which are sensors of intracellular lipid conversion, are engaged in the synthesis of cholesterol (SREBP-1 and -2), FA and TAG (SREBP-1c). Polyunsaturated FA, as well as some conjugated linoleic acid (CLA) isomers, modulate the content of liver mRNA encoding SREBP-1c or directly transcription of SREBP-1c. It has been shown that PUFAs inhibit expression of SREBP. No corresponding effect of PUFA on adipose tissue has been found. Both n-3 and n-6 PUFA suppress ChREBP/MLX and interfere with glucose-regulated hepatic metabolism. As a result of the above effects of PUFA on transcription factors, PUFAs promote FA oxidation and prevent FA synthesis and storage ${ }^{33,34}$.

\section{b. Receptor interactions and signal transduction}

Amide derivatives of FA were intensively studied in the fifties. N-palmitoylethanolamine from soya and egg yolk has been shown to have antiinflammatory action. Ethanolamine, ammonia and some bioactive amines are donors of the amino group in the reaction with FA. The resulting amides interact with cannabinoid as well as vaniloid receptors. Brain cannabinoid receptors take part in signal pathways of memory, movement, emotional and nociceptive processes. On the other hand, peripheral cannabinoid receptors play a role in the modulation of immunocompetent cells ${ }^{37}$.

Ethyl esters of FA, products of the non-oxidative metabolism of ethanol, are produced by a specific synthase. This results from chronic ethanol use. These esters can be ligands of PPAR, and other transcription factors, such as NFkB and activator protein 1 (AP-1) (ref. ${ }^{38}$ ). Nuclear factor $\kappa \mathrm{B}$ exists in the cytosol of inflammatory cells in an 
inactive form (heterotrimer) and upon activation it induces expression of various inflammatory factors such as TNF- $\alpha$, IL-1, -6, COX-2. Stimulation of inflammatory cells leads to activation of a protein complex which degrades the inactive form of NFKB to an active heterodimer which can be translocated to the nucleus and bind to response elements affecting gene transcription. Evidence suggests that LC n-3 PUFA may act as inhibitors of the NFkB activation pathway, thus, reducing inflammation ${ }^{23,36}$.

The receptor of platelet activating factor (PAF, 1-O-alkyl-2-acetyl-sn-glycerol-3-phosphocholine) recognises PAF, which contains an ether bond in the sn-1 position of glycerophosphocholine and a residue of short FA in the sn-2 position, with high specificity ${ }^{39}$.

Enteroendocrine L cells are found throughout the gastrointestinal tract epithelium among enterocytes. L cells are activated by food components and their metabolites in the lumen, resulting in secretion of gut hormones. Specifically, 7TM G protein-coupled receptors, mostly found on the apical pole of L cells, function as chemosensors. Amongst other receptors, L cells have chemosensors for LCFA (GPR40, GPR120) and SCFA (GPR41, GPR434), the latter being degradation products (propionic, acetic, butyric acids) of complex polysaccharides by gut microbiota ${ }^{40}$. Samuel et al. (ref. ${ }^{41}$ ) showed that the GPR41 receptor on L cells is essential for SCFA to act as a fuel and as signalling molecules. Reimann et al. (ref. ${ }^{42}$ ) managed to genetically tag L cells and culture them, in order to investigate secretion of glucagon-like peptide-1 (GLP-1) from L cells. This is an enteric hormone that stimulates insulin secretion and improves glycemia in Type 2 Diabetes. L cell chemosensor receptors are interesting drug targets to tackle metabolic disorders, diabetes, obesity and even cancer cachexia. Current studies focus on novel treatments including GLP-1, GLP-2, peptide YY (PYY), and ghrelin mimetics ${ }^{40}$. A potential drug target could be the above mentioned LCFA and SCFA chemosensor receptors.

\section{Interactions between fatty acids and non-receptor proteins}

Some FAs (oleic, palmitoleic, arachidonic) are potent uncoupling agents of cell communication at the level of gap junctions (cell connecting proteins). The mechanism of action lies in the interaction between lipids and cell connecting proteins, specifically in myocytes ${ }^{43}$.

Ion channels can be affected by FAs. Calcium channels of ventricular myocytes are directly activated by LC PUFAs. The effect of DHA on the creation of slow potassium rectifying current is caused by its effect on the hminK subunit of calcium channels. Sodium channel isoforms in the heart and muscle tissue are inhibited by different types of FA. The antiarrhytmic effects of LC n-3 PUFA are probably associated with these interactions ${ }^{44}$.

\section{FATTY ACIDS IN HEALTH AND DISEASE}

\section{Nutrition recommendations}

Nutritional recommendations regarding fat intake have been formulated by various bodies in Europe and worldwide, including: the German-Austrian-Swiss body $^{45}$, the Nordic Nutrition ${ }^{46}$, the UK Committee on Medical Aspects of Food policy ${ }^{47}$, the Nutritional Recommendations for the French Population ${ }^{48}$, the Health Council of the Netherlands ${ }^{49}$, the Dietary Guidelines for Americans ${ }^{50}$, and the World Health Organisation ${ }^{51}$. Recently, the European Food Safety Authority (EFSA) Panel on Dietetic Products, Nutrition, and Allergies (NDA) (ref. ${ }^{8}$ ) has reviewed these recommendations and scientific evidence available, and published a scientific treatise on Dietary Reference Values (DRV) for fats.

Dietary fat is one of the main energy substrates. It is recommended that total fat should be between a minimum of $20 \%$ and a maximum of $35 \%$ of TEI through food consumed by healthy adults ${ }^{8}$. Fat intake for infants should be $40 \%$ of TEI between 6-12 months of age, and reduced to $35-40 \%$ of TEI for children aged 2-3 years old. It was proposed by EFSA that SFA and trans FA intake should be as low as possible (without setting a DRV), and that no DRV can be formulated for cis-monounsaturated FA (MFA) or cis-PUFA ( ref. $^{8}$ ). However, other bodies have set more specific targets for these types of fat. The above mentioned European and worldwide bodies recommend intake of $<10 \%$ of TEI for SFA, and $<1-2 \%$ of TEI for trans FA. Also, adult intake of cis-MFA is recommended to be $10-15 \%$ of TEI by the Nordic Nutrition Organisation, whereas in France the recommendation reaches 20\% of TEI. For $c i s$-PUFA it has been recommended that intake should be between $5-10 \%$ of TEI (ref. ${ }^{45-50}$ ). These recommendations are modified for impaired conditions where fat intake (mainly that of SFA) should be lower, such as in coronary heart disease (CHD), hypertriacylglycerolemia, diabetes, and the metabolic syndrome. According to the Therapeutic Lifestyle Changes (TLC) in LDL-lowering therapy of the Adult Treatment Panel III (ref. ${ }^{52}$ ) for CHD and $\mathrm{CHD}$ risk equivalents, it has been recommended that SFA intake should be $<7 \%$ of TEI, PUFA up to $10 \%$ and MFA up to $20 \%$ of TEI. Also, dietary cholesterol intake should be limited to $<200 \mathrm{mg} /$ day $^{52}$.

As far as EFAs are concerned, EFSA suggested an Adequate Intake (AI) of $4 \%$ of TEI for LA and $0.5 \%$ of TEI for ALA. Both, EFSA and the WHO have agreed that there is insufficient scientific evidence to support a recommendation for the $n-3$ to $n-6$ PUFA ratio; thus no DRV was set. Specific recommendations were given for LC n-3 PUFA. Increased dietary intake of preformed DHA is imperative for adequate DHA status in adults and infants, which cannot be achieved by DHA precursor supplementation (ALA, EPA) (ref. ${ }^{5}$ ). EFSA and the WHO (ref. ${ }^{8,51}$ ) set an AI of $250 \mathrm{mg}$ for EPA plus DHA for adults. Specifically for infants and young children $(<24$ months) it was recommended that DHA AI should be $100 \mathrm{mg}$. During pregnancy and lactation it was recommended that additionally to the AI for LC n-3 PUFA, intake of DHA should be increased by 100-200 mg. Also, other bodies have recommended that DHA intake should be at least $200 \mathrm{mg} /$ day in women of reproductive age ${ }^{53}$, that pregnant women need to consume a minimum of 300 mg DHA/day ${ }^{54}$, and that lactating women should aim to achieve an average dietary intake of at least $200 \mathrm{mg}$ DHA/ 
day $^{55}$. The current UK and Dutch recommendation for EPA plus DHA intake for the general adult population is at least $450 \mathrm{mg} /$ day $^{56}$. To achieve this level of intake, COMA recommended eating at least two portions of fish, of which one should be oily, weekly ${ }^{56}$. The average fish portion size for adults is defined $140 \mathrm{~g}$, and the estimate used for long-chain n-3 PUFA (EPA and DHA) content of an average oily fish is $1.5-2 \mathrm{~g} / 100 \mathrm{~g}$ and for an average white (non-oily) fish $0.3 \mathrm{~g} / 100 \mathrm{~g}$. It is underlined that pregnant women and women of reproductive age should not consume more than a total of two portions of oily fish and tinned tuna per week because of the possible high levels of mercury and other contaminants in these fish. For the same reason, pregnant women are advised to avoid eating shark, marlin and swordfish ${ }^{56}$. Lastly, the WHO (ref. ${ }^{51}$ ) set an upper level of acceptable macronutrient distribution range (U-AMDR) for LC n-3 PUFA (EPA plus DHA) of $2 \mathrm{~g}$ /day, recognising that at this level of intake or higher LC n-3 PUFA may have cardioprotective effects and may be used for secondary prevention of CHD. This upper level of intake has been set at $3 \mathrm{~g}$ /day by USA and Australia/New Zealand bodies ${ }^{57}$. Further randomised clinical trials and research would help to clarify the upper level of intake of LC n-3 PUFA (ref. ${ }^{58,59}$ ).

\section{Fatty acids in maternal and offspring health}

Gestation, as well as the first months of life, are critical periods of organ development for the fetus and the newborn ${ }^{60}$. Environmental exposures of the mother during gestation may predispose the fetus in utero to modulating factors affecting health outcomes ${ }^{61}$. Moreover, exposure to specific nutrients and factors via breast milk is critical for development ${ }^{62}$. With regards to this, many factors have been characterised to be crucial in development such as exposure to pollutants, intake of folic acid, vitamin D, antioxidants such as selenium ${ }^{63-65}$, and most importantly FA (ref. ${ }^{66,67}$ ). Fatty acids are important biocompounds playing major roles for maternal, fetal and infant health. The role of FA during gestation, including maternal FA metabolism and storage, placental FA composition and function, fetal FA supply in utero and its effects on developmental outcomes, as well as the importance of breast milk and postpartum fatty acid supply to the infant will be discussed in this section.

\section{a. Fatty acids during gestation: maternal and placental metabolism}

During pregnancy there are two principal metabolic stages. During the first two trimesters fetal growth is limited and the mother accumulates nutrients and energy in her body stores. The last trimester is characterised by a catabolic phase whereby maternal adipose tissue lipolysis releases FA to the maternal circulation which will be transferred to the fetus through the placenta ${ }^{68}$. Maternal non-esterified FA (NEFA) released from lipolysis are mainly re-esterified into TAG in the liver, and these are released into the circulation in the form of VLDL. There is an increase in plasma TAG concentration during late gestation and this is termed the hypertriacylglycerolemia of pregnancy ${ }^{68}$. Also, during late pregnancy levels of TAG increase in LDL and HDL probably associated with increased activity of the cholesteryl ester transfer protein (CETP) (ref. ${ }^{69}$ ). This enzyme controls TAG and CE exchange between VLDL, LDL, and HDL. Maternal hypertriacylglycerolemia is considered to be beneficial for the fetus, as it may enhance the availability of important FA from the mother. During late pregnancy, intestinal absorption of TAG is very efficient and TAG are carried in the form of chylomicrons in maternal plasma ${ }^{70}$.

The function of the placenta and many physiological and metabolic adaptations taking place during pregnancy play a fundamental role in optimising the transport of FA to the fetus ${ }^{71}$. Complex mechanisms are involved in placental fatty acid transport ${ }^{72}$. Lipoproteins can be takenup by the placenta by lipoprotein receptors existing in the placenta. Also, because of the expression of lipoprotein lipases (LPL) on placenta, maternal TAG can by hydrolysed and the NEFA released can by taken up by the placenta. These can be re-esterified and stored, and then hydrolysed and released into the fetal bloodstream ${ }^{68}$.

Transport of LC PUFA to the placenta is mainly done by uptake of maternal TAG intact in plasma ${ }^{73}$. This is suggested to be greater than uptake of NEFA from the placenta. However, maternal plasma NEFA bound to albumin are also a source of LC PUFA for the fetus ${ }^{69}$. Thus, FA to be transported by the placenta are derived mainly from TAG in chylomicrons or VLDL, from which they are released by TAG hydrolase/LPL before entering the placenta. The placenta uptake of circulating TAG is concentration gradient dependent ${ }^{74}$.

Placenta FA composition can be indicative of maternal fatty acid status and reflects FA which are selectively transferred to the fetus. The placenta is mainly composed of phospholipids which comprise about $88 \%$ of total lipids $^{72}$. The placenta is dominated by PUFAs, followed by SFA (mainly palmitic and stearic acids), and MFA (mainly oleic) in lower percentages. Arachidonic acid is the major PUFA in placenta tissue. Its levels (about 22$25 \%$ ) are higher than that of DHA and EPA, as well as LA and dihomo-gamma-linolenic acid (DGLA). Also, LA and DGLA (n-6 PUFA) are found in higher levels compared to placental LC n-3 PUFA (ref. ${ }^{72,74,75}$ ). In relation to this, AA- derived PG are related to the maintenance of pregnancy and initiation of labor ${ }^{76}$.

The presence of membrane FA binding protein in human placenta results in preferential transfer of certain FAs to the fetus. It has been well demonstrated that maternal and cord plasma at delivery have a different fatty acid profile in almost all lipid fractions (including $\mathrm{CE}$ and PC), with umbilical cord plasma exhibiting a higher concentrations of AA and DHA. This indicates selective mobilisation of LC PUFAs from the placenta and their preferential supply to the fetus ${ }^{77,78}$. Also, it has been shown that pregnancy is associated with a decline in percentage levels of AA and DHA in maternal plasma TAG, which may indicate the selective transfer of these FAs to the fetus ${ }^{79}$. Preferential transfer of LC PUFA (mainly DHA) is higher than EFA transfer ${ }^{72,74}$. The fetus depends on placental LC PUFA supply because fetal $\Delta 6$ - and $\Delta 5$ desaturase activity is very low in utero, and the placenta 
lacks enzymatic activity for the conversion of EFA to LC PUFA (ref. ${ }^{71,74}$ ).

Various studies have shown that maternal plasma and red blood cell FA percentages were highly significantly correlated with fetal and neonatal FA (ref. ${ }^{80,81}$ ). Also, it has been demonstrated that maternal LC n-3 PUFA dietary intake during pregnancy was positively associated with maternal blood levels and significantly correlated with cord blood levels of these FA (ref. ${ }^{82,83}$ ). Consequently, maternal dietary intake of LC PUFA is related to the availability of these FAs to the fetus ${ }^{71}$.

During pregnancy a woman must meet the additional demands related to the accretion of maternal, placental, and fetal tissues. Although, the formation of DHA and EPA appears to be tightly regulated, a marginal state for many women during pregnancy and lactation cannot be excluded ${ }^{56}$. Also, maternal LC n-3 PUFA status decreases with the number of consecutive pregnancies ${ }^{84,85}$. Therefore, it is imperative for women of reproductive age to sustain a good LC n-3 PUFA status in order to support fetal demands of present and future pregnancies.

Excess intake of total fat during pregnancy, mainly trans and saturated fat, can lead to gestational hyperglycemia and gestational diabetes mellitus, whereas PUFA intake is linked with a lower risk ${ }^{86}$. Similarly, increased intake of LC n-3 PUFA may be protective against preeclampsia ${ }^{87}$.

\section{b. Fatty acids in utero: fetal growth and development}

Fatty acids are required by the developing fetus in order to maintain fluidity and structure of membranes, as well as to act as precursors of eicosanoids ${ }^{71}$. Longchain PUFA (mainly DHA and AA) are important for fetal growth and development ${ }^{72,74}$ and they influence length of gestation ${ }^{88-94}$. It was shown that maternal DHA status in early gestation was positively associated with birth weight and head circumference ${ }^{95}$. Lengthening of gestation results in lower risk of preterm birth is beneficial for both the mother and the fetus. Systematic reviews and meta-analyses have concluded that: maternal LC PUFA supplementation reduced preterm delivery ${ }^{96}$, marine oil supplementation mildly increased the length of gestation ${ }^{97}$, fish oil supplementation during pregnancy decreased the risk of preeclampsia, preterm birth, low birth weigh and small-for-gestational age ${ }^{98}$. The effect of fish oil supplementation on gestational length seems to be more evident in women with a low or moderate habitual intake of fish ${ }^{93}$.

Docosahexaenoic acid is accumulated in high concentrations in the membranes of cells of the fetal nervous and visual systems (i.e. in fetal brain and retina) during pregnancy ${ }^{99}$, and this accumulation is very important for visual and cognitive development both before and after birth ${ }^{100}$. High amounts of DHA are incorporated into membranes in the brain and retina especially during the last trimester of pregnancy, when fetal nervous system growth is very rapid $^{74}$. Total fetal DHA accretion in utero takes place mainly in the last 10 weeks of pregnancy ${ }^{71}$. Most of the DHA is stored in fetal adipose tissue in utero (50 times more than in fetal brain) in order to be released after birth and utilised for growth. Accretion of LC PUFA in utero results in higher concentration of DHA and AA in the fetal adipose tissue compared to maternal ${ }^{71}$. In general, LC PUFA levels increase from maternal tissues to fetal circulation to fetal tissues (known as biomagnification) (ref. $\left.{ }^{101}\right)$.

It is known that preterm birth, which curtails maternal supply of DHA to the fetus, is associated with sub-optimal neural and visual development, which can be improved by providing exogenous DHA (ref. ${ }^{55,102}$ ). Several maternal fish oil supplementation studies during the second half of gestation have shown that maternal and cord blood EPA and DHA status are improved following supplementation $^{103,104}$. Maternal supplementation with LC n-3 PUFA during pregnancy ${ }^{89,105,106}$, or lactation ${ }^{107-110}$, or both ${ }^{111,112}$ have been shown to result in improved cognitive and/or visual function. These studies have been recently reviewed by Brenna \& Lapillonne (2009) (ref. ${ }^{113}$ ).

Long chain n-3 PUFA have also been shown to influence immune function ${ }^{67}$. A point to be considered is the origin of n-3 PUFA. It was recently shown in a rat study, that fish oil, but not linseed oil, intake during pregnancy reduced antibody response in the offspring and potentially increased T-helper type 1 (Th1) polarisation ${ }^{114}$. It has been shown that LC n-3 PUFA status in maternal blood and umbilical cord blood is lower in mothers of allergic (atopic) children ${ }^{115,116}$. It is now considered that supply of EPA and DHA to the fetus might be important in promoting appropriate immune development ${ }^{117,118}$. With regard to the latter, there is some evidence that early fish and LC n-3 PUFA exposure protects against immune dysfunctions like sensitisation to allergens (atopy), allergy and asthma in infancy and childhood ${ }^{119}$. Epidemiological studies looking at the effect of maternal fish consumption during pregnancy and fish consumption during infancy/childhood suggest that fish consumption may play a protective role against atopic disease development in children. It has been shown that fish oil supplementation during pregnancy and lactation resulted in higher LC n-3 PUFA provision and status in the offspring ${ }^{93,103,120-123}$. Early fish oil provision was associated with immunologic changes in cord blood which may be consistent with decreased risk of atopy in the offspring and such changes may persist ${ }^{118}$. These studies suggested clinical benefits of early fish oil provision including reduced sensitization to common food allergens and reduced prevalence and severity of atopic dermatitis in the first year of life, again with a possible persistence until adolescence with a reduction in eczema, hay fever, and asthma. Also, studies of fish oil supplementation during infancy or childhood have shown protective effects, although the evidence is heterogeneous ${ }^{119}$.

\section{c. Fatty acids postnatally: breast milk and infant development}

Maternal breast milk is of great importance in humans and other mammals since it is the main source of all nutrients for the newborn. Early exposure of the newborn to specific factors through breast milk including FA, immunoglobulins, minerals, vitamins, but also possible environmental pollutants including maternal smoking ${ }^{124,125}$, 
is fundamental in modulation and programming of health and disease outcomes later on in life.

Breast milk fatty acid composition is very much dependent on maternal dietary fat intake during gestation which is deposited in adipose tissue and released into breast milk during lactation. Thus, the type of dietary fat consumed during pregnancy will determine not only the fatty acid profile of the mother and the fetus, but also that of breast milk to be provided to the newborn ${ }^{126}$. In relation to this, maternal fish oil supplementation during gestation significantly increased breast milk content in LC n-3 PUFA (ref. ${ }^{126,127}$ ). However, there are also LC n-3 PUFA supplementation studies during lactation showing increased breast milk EPA and DHA content after supplementation $^{107,128-130}$. Moreover, dietary trans FA intake during pregnancy and lactation are directly related to breast milk concentration of trans FA (ref. ${ }^{131,132}$ ).

Preformed LC n-3 PUFA, particularly EPA and DHA, need to be provided to infants to meet the high requirements of rapidly growing tissues and organs ${ }^{56}$. The human brain growth spurt initiates at week 28 gestation and continues during the first year of life ${ }^{133,134}$, while AA and DHA are important also during the second year ${ }^{135}$. Obviously, the brain is the most critically developing tissue postpartum. It is composed of specific lipids like sphingosinederived lipids and other phospholipids. About 50\% of FA in brain lipids are n-3 PUFA, like EPA and DHA. Phosphatidylcholine (lecithin) is one of the most important phospholipids in brain tissue (approx. 10\% of dry weight). Although, LC n-3 PUFA are released from the neonate's adipose tissue, their exogenous source is breast milk which in humans is rich in these FA and PC during the first weeks of lactation. Breast milk fat content is about $3-4 \%$ by weight and fat provides about $50-60 \%$ of total energy. Human milk provides mainly SFA (palmitic) and MFA (oleic) $\left(\right.$ ref. $\left.^{136}\right)$. Typically, DHA (0.2-1\%) and AA $(0.3-0.7 \%)$ are the dominant LC PUFA in breast milk, with DHA being more variable and sensitive to maternal dietary intake ${ }^{137,138}$. Sphingomyelin is one of the quantitatively most important components of breast milk; its level seems to be rather constant for at least 3 months. Breast milk contains more sphingomyelin than cow's milk, which is also an important source of this compound. Also, human and cow's milk contain PUFA and choline. Thus, breast milk is a great source of the fundamental lipids for brain development. In the case of neonates that are not being breastfed, fish oil supplemented infant milk formulas are used ${ }^{134,139}$. The adult brain needs constantly the provision of the same nutrients (sphingomyelin) as that of a developing child. Cow's milk is probably a valuable source of these compounds. Therefore, dairy products are important components of the human diet. However, as a significant number of adults do not consume enough dairy products, these important nutrients should be obtained from other foods, such as oily fish which are rich sources of LC n-3 PUFA.

Breast milk FA content is also important for other aspects of neural development, such as cognition and vision, as well as immune development of the infant. There is some evidence from observational ${ }^{140-142}$ and fish oil supplementation studies ${ }^{107,110,111,143}$ showing a significant positive correlation between visual acuity and cognitive function later on in infancy and childhood and DHA levels in breast milk or infant DHA status. Also, there is evidence that LC n-3 PUFA status in breast milk is lower in mothers of allergic (atopic) children ${ }^{115,116,144,145}$. Thus, increased intake of LC n-3 PUFA through breast milk may be protective against allergic disease development ${ }^{120,146,147}$. On the other hand, it was recently shown that increased maternal intake of butter and SFA during lactation was associated with increased risk of allergic sensitisation in the offspring at age 5 years ${ }^{148}$. Lastly, increased provision of LC n-3 PUFA later on in infancy and early childhood (through increased oily fish consumption or LC PUFA supplementation) has also been shown to decrease the risk of allergic disease development ${ }^{149-152}$ and has been associated with better visual acuity ${ }^{153,154}$ and cognitive function $^{155,156}$, although these effects need to be further investigated. The effects of PUFA on child attention deficit and hyperactivity disorders are not yet clear as the existing evidence is inconclusive ${ }^{157}$.

Genetic polymorphisms in FA desaturase genes modify the association between FA intake and maternal and breast milk FA status. Also, genetic variability in pregnant women may affect FA provision to the fetus and thus its growth and development. The beneficial effects of breast feeding can be altered by the mother-infant-pair genotype. Gene-diet interactions should be taken into account when investigating the effects of maternal diet on the offspring health ${ }^{7}$.

\section{Fatty acid pathophysiology and gene interactions}

Fatty acid composition is primarily determined genetically and it is tissue and species specific. Dietary fat influences fatty acid status and is reflected in fatty acid composition of plasma and adipose tissue ${ }^{158-160}$. A number of pathological stages may accompany changes in fatty acid composition due to increased intake of animal fat and decreased intake of vegetable and marine origin oils ${ }^{161-164}$. This is often expressed as decreased content of PUFA (mainly n-3 PUFA) and increased content of SFA in states such as dyslipidemia, malnutrition, inflammation, oxidative stress, inherited diseases, and other common metabolic abnormalities (metabolic syndrome, Type 2 diabetes).

The variation in desaturase genes, as part of complex gene-lifestyle interactions, has an important role in determining plasma lipid profiles. This introduces a nutrigenomics approach to disease control and prevention $^{7}$. Polymorphisms in the genes encoding $\Delta 5$ - and $\Delta 6$ desaturases, FADS1 and FADS2 respectively (chromosome 11q12-11q13.1), have been associated with PUFA and LC PUFA status and cholesterol levels. A case-control study in Korea showed that the T allele of the single nucleotide polymorphism (SNP) rs 174537 (flapstructure specific endonuclease; FEN1) near FADS1 was associated with lower risk of coronary artery disease. Also, T allele FEN1 carriers had significantly higher levels of LA and lower levels of AA compared to $\mathrm{G} / \mathrm{G}$ subjects. This was also associated with reduced total and LDL-cholesterol and 
Table 2. Factors influencing the activity of desaturases and elongases.

\begin{tabular}{|c|c|c|}
\hline Enzyme & Activation & Inhibition \\
\hline \multirow{6}{*}{$\Delta 6$-desaturase } & \multicolumn{2}{|c|}{ Nutrition factors } \\
\hline & $\begin{array}{l}\text { ATP } \\
\text { deficiency of EFA } \\
\text { deficiency of Phe, Tyr } \\
\text { high-protein diet } \\
\text { fat-free diet } \\
\text { Zn, Mg } \\
\text { pyridoxine }\end{array}$ & $\begin{array}{l}\text { ethylalcohol } \\
\text { fasting } \\
\text { glucose, glycerol } \\
\text { deficiency of proteins } \\
\text { deficiency of pyridoxine } \\
\text { exogenous cholesterol } \\
\text { n-3 and n-6 PUFA }{ }^{1} \\
\text { SFA } \\
\text { excess intake of Phe and Tyr } \\
\text { trans-MFA }\end{array}$ \\
\hline & \multicolumn{2}{|c|}{ Hormonal factors } \\
\hline & Insulin & $\begin{array}{l}\text { glucagon (cAMP) } \\
\text { adrenalin (cAMP) } \\
\text { glucocorticoids } \\
\text { ADH, ACTH } \\
\text { hyper-, hypo-T } 3, \mathrm{~T}_{4}\end{array}$ \\
\hline & \multicolumn{2}{|c|}{ Other factors } \\
\hline & $\begin{array}{l}\text { decreased external temperature } \\
\text { fasting/ re-feeding }\end{array}$ & $\begin{array}{l}\text { raised external temperature } \\
\text { aging } \\
\text { radiation } \\
\text { oncogenic viruses }\end{array}$ \\
\hline$\Delta 5$-desaturase & $\begin{array}{l}\text { insulin } \\
\text { LA, GLA, AA } \\
\text { columbinic acid }^{2}\end{array}$ & $\begin{array}{l}\text { fat-free diet } \\
\text { exogenous cholesterol } \\
\text { trans-MFA } \\
\text { deficiency of proteins } \\
\text { glucose } \\
\text { vitamin A } \\
\text { PUFA n-3 } \\
\text { glucagon, adrenalin } \\
\text { glucocorticoids }\end{array}$ \\
\hline Elongase & $\begin{array}{l}\text { glucose supply } \\
\text { deficiency of EFA } \\
\text { fat-free diet }\end{array}$ & fasting \\
\hline
\end{tabular}

120:5 n-3, 22:5 n-3, 22:6 n-3, 18:3 n-6, 20:3 n-6

${ }^{2}$ trans,cis, cis-octadeca $-5,9,12$ - trienoic acid

AA, Arachidonic acid; ACTH, Adrenocorticotropic hormone; ADH, Antidiuretic hormone; AMP, Adenosine monophosphate; ATP, Adenosine triphosphate; EFA, Essential fatty acid; GLA, $\gamma$-Linonenic acid; LA, Linoleic acid; MFA, Monounsaturated fatty acid; Phe, Phenylalanine; PUFA, Polyunsaturated fatty acid; SFA, Saturated fatty acid; $\mathrm{T}_{3}$, Triiodothyronine; $\mathrm{T}_{4}$, Thyroxine; Tyr, Tyrosine.

lipid peroxides (malondialdehyde, oxidised-LDL) $\left(\right.$ ref. $\left.^{165}\right)$. In the Doetinchem Cohort Study, it was concluded that dietary intakes of n-3 and n-6 PUFA interact with FADS1 polymorphism to affect plasma total and HDL-cholesterol levels ${ }^{166}$. In populations consuming a Western diet, it has been shown that the FADS polymorphism which is associated with higher desaturase activity may result in higher risk of proinflammatory response, and thus, atherosclerosis $^{167,168}$. Also, carriers of the rare allele of FADS SNP and their haplotypes had altered eicosanoid precursor levels and a lower prevalence of allergic disease and topical ec- zema $^{169}$. Interactions have also been shown between the APOA 5 and FEN1 polymorphisms and AA and n-6 PUFA levels in serum phospholipids and coronary artery disease $^{170}$. Further, polymorphisms at the 5-LOX and COX-2 level have been shown to increase the risk of CHD and prostate cancer respectively, depending on DHA, EPA, LA and ALA intake. Thus, studies investigating the association between genetic variation and disease should include diet (and FA intake) in their analysis ${ }^{171}$. As blood levels of PUFA are not only diet-dependent, but also influenced by genetic variants, it has been suggested that 
dietary requirements of PUFA should take into account these genetic polymorphisms. Also, FADS polymorphism analyses should be included in studies focusing on the biological effects of PUFAs ( ref. $^{172}$ ).

It is interesting that metabolic disorders of different manifestation, such as extreme leanness in anorexia nervosa and obesity in the metabolic syndrome, result in similar changes in FA lipid profile. A characteristic marker in both disorders is the increased content of palmitoleic acid (also a marker of liponeogenesis). This results from increased activity of $\Delta 9$-desaturase which converts palmitic to palmitoleic acid. A second marker is the decreased content of LA which probably results from several factors (decreased food intake, increased peroxidation and $\beta$-oxidation, increased conversion of AA to eicosanoids) (ref. ${ }^{173,174}$ ). Anorexia nervosa, a condition of extreme starvation, has been characterised by changes in plasma lipids and lipoproteins. Specifically, it was shown that patients with anorexia nervosa had raised total cholesterol, TAG, HDL-cholesterol, campesterol, and $\beta$-sitosterol. Also, there was a decrease in n-6 PUFA and LA, and an increase in palmitoleic acid in all plasma lipid classes ${ }^{173}$. The common SNP (C to T substitution) in the first intron of the FA coenzyme A ligase-4 (FACL4) gene has been investigated in relation to FA metabolism in the metabolic syndrome and in depression. In metabolic syndrome patients, $\mathrm{T}$ allele carriers were characterised by higher content of DGLA and lower content of AA in plasma PC, lower index of $\Delta 5$ desaturation and unsaturation index. The studied SNP was not associated with markers of FA metabolism in depressed patients ${ }^{175}$.

\section{Essential fatty acid deficiency}

Fatty acid status depends (apart from other factors such as genetics and the diet) on the activity of desaturation and elongation enzymes of their metabolic cascade ${ }^{176}$.
Factors influencing the activity of these enzymes are summarized in (Table 2).

Deficiency of EFA leads to a number of disorders, which are summarised in (Table 3). Essential FA deficiency has been known since the 30's of the last century ${ }^{177}$. In animal experiments, EFA deficiency was linked to growth retardation and increased transepidermal losses of water as a result of increased skin permeability. In both males and females, EFA deficiency causes infertility and it results in a lower AA content which is an eicosanoid precursor $^{178-180}$. Also, there is an increased desaturation and elongation of oleic acid to Mead acid (20:3n-9) in order to preserve membrane fluidity and produce alternative precursors for eicosanoid synthesis ${ }^{181,182}$. Increased fragility of capillaries and haematuria is linked to disrupted biomembrane stability. Experiments showed increased food consumption in animals with negative nitrogen balance and lowered production of ATP in parenchymal organs (liver, myocardium); this effect is related to decreased contractility of the myocardium and abnormal QRS in electrocardiogram. Essential FA deficit in the liver leads to lower cholesterol transport, probably connected to secondary dyslipidemia and slower reverse cholesterol transport. Clinical markers include abnormal adaptation to darkness (dysopsia) and lower visual acuity, as well as motor neuropathies ${ }^{183-185}$. In the 90's, the pathophysiological and clinical differences between n-3 and n-6 PUFA deficiencies were defined as shown in (Table 4).

\section{Oxidative stress}

Dietary supplementation with n-3 PUFA had been related to enhanced oxidative stress and increased oxidative modification of LDL in comparison to n-6 PUFA supplementation. However, new findings suggest that incorporation of PUFA into phospholipids leads to conformational changes and lowered availability of double bonds for lipoperoxidation. Also, the peroxyl radicals derived from

Table 3. Essential fatty acid deficiency syndrome.

Growth disturbances
Increased transepidermal losses of water (increased skin permeability)
Increased predisposition to bacterial infections
Male and female infertility
Decreased status of AA/ increased status of Mead acid (20:3n-9)
Disturbed stability of biomembranes
Disturbed cholesterol transport
Increased fragility of capillaries
Kidney failure (haematuria, hypertension)
Lower contractility of myocardium
Abnormal QRS in electrocardiogram
Lowered production of ATP (myocardium, liver)
Dysopsia (lowered visual acuity, disturbed adaptation to darkness)
Neurological disturbances (sensor and motor neuropathies)
Increased food demand with negative nitrogen balance
Disturbed synthesis of eicosanoids


Table 4. Comparison of n-3 and n-6 polyunsaturated fatty acid deficiencies.

\begin{tabular}{|c|c|c|}
\hline Deficiency & n-3 PUFA & n-6 PUFA \\
\hline $\begin{array}{l}\text { Clinical } \\
\text { symptoms }\end{array}$ & $\begin{array}{l}\text { normal skin, growth and reproduction } \\
\text { abnormal electroretinogram } \\
\text { dysopsia } \\
\text { polydipsia }\end{array}$ & $\begin{array}{l}\text { growth retardation } \\
\text { skin lesions } \\
\text { disturbed reproduction } \\
\text { steatosis } \\
\text { polydipsia }\end{array}$ \\
\hline $\begin{array}{l}\text { Biochemical } \\
\text { parameters }\end{array}$ & $\begin{array}{l}\downarrow 18: 3 n-3 \text { and } 22: 6 n-3 \\
\uparrow 22: 4 n-6 \text { and } 22: 5 n-6 \\
\uparrow 20: 3 n-9 \text { (only with parallel } \downarrow \text { of PUFA } n-6)\end{array}$ & $\begin{array}{l}\downarrow 18: 2 \mathrm{n}-6 \text { and } 20: 4 \mathrm{n}-6 \\
\uparrow 20: 3 \mathrm{n}-9 \text { (only with parallel } \downarrow \text { of PUFA n-3) }\end{array}$ \\
\hline
\end{tabular}

PUFA, Polyunsaturated fatty acid.

EPA are more hydrophilic than those generated from LA. They diffuse more readily through lipoprotein envelopes and radical reaction can be terminated more rapidly on the lipoprotein surface ${ }^{186,187}$.

Increased dietary intake of n-3 versus n-6 PUFA results in enhanced transcription of antioxidant enzymes (uncoupling protein 2 , glutathione transferase $2 \tau$, superoxide dismutase) and in suppressed transcription of enzymes taking part in the production of reactive oxygen and nitrogen species (RONS). Intake of n-6 PUFA increased activities of glutathione peroxidase, superoxide dismutase and catalase ${ }^{187,188}$. Increased severity of the metabolic syndrome has been associated with increased oxidative stress and unfavourable fatty acid metabolism. Increased severity of the metabolic syndrome was also linked to increased content of SFA and activities of $\Delta 9$ - and $\Delta 6$ - desaturases, decreased content of n-6 PUFA and $\Delta 5$-desaturase activity ${ }^{189}$. Also, in men with the metabolic syndrome, the presence of the T allele of the microsomal TAG transfer protein (MTP) -493G/T polymorphism was associated with increased NEFA, plasma total cholesterol, plasma TAG, and VLDL. Carriers of the T allele had lower concentrations of plasma n-6 PUFA in phospholipids, lower $\Delta 5$-desaturase activity and higher concentrations of conjugated dienes in LDL. These effects were not observed in healthy men or in women (with or without metabolic syndrome) (ref. $\left.{ }^{174}\right)$.

\section{Cardiovascular health and blood lipids}

Excess intake of fat predisposes to higher risk of impaired postprandial lipidemia which triggers a proinflammatory state and results in increased risk of cardiovascular disease (CVD) (ref. ${ }^{190,191}$ ). However, different effects are caused by different types of fat consumed ${ }^{162,192}$ also depending on genetic polymorphisms. Carriers of FADSI and FADS2 haplotypes which are associated with higher desaturase activity had higher risk for coronary artery disease and inflammation ${ }^{167}$. Increased SFA intake is linked to increased plasma LDL-cholesterol levels and increased risk of $\mathrm{CVD}^{190}$, although stearic acid seems to have milder effects ${ }^{193-195}$. Also, the effect of increased trans FA intake has been well documented to be negative since it promotes CVD development ${ }^{196,197}$. Milk contains also trans FA (predominately trans vaccenic and rumenic acids) but probably humans have adapted to these levels (see part 1 of this review). When plant oils are hydrogenated different trans FA are formed. Elaidic acid is a characteristic trans FA which is generated by low quality catalysis during margarine production. Technologies have been developed to minimise trans FA production in industrial and cooking processes $^{198}$, although they still appear in food consumed. Further advances in these technologies are required.

In contrast, high MFA intake from olive oil has been shown to be cardioprotective, resulting in increased HDL-cholesterol and decreased LDL-cholesterol. Also, the Mediterranean dietary pattern which is characterised by high consumption of olive oil has been related to lower risk of cardiovascular disease mortality ${ }^{199}$. As far as PUFAs are concerned, various studies have shown that their effect is beneficial compared to SFA (ref. ${ }^{190}$ ). However, differential effects are caused by n- 6 and n-3 PUFA (ref. ${ }^{161}$ ), with a greater cardioprotective effect shown for n-3 PUFA (ref. ${ }^{200}$ ). In a recent meta-analysis it was shown that increasing intake of n-6 PUFA alone increases the risk of myocardial infarction and CHD death compared to simultaneously increasing n-6 and n-3 PUFA $\left(\right.$ ref. $\left.{ }^{201}\right)$.

Increased intake of n-6 PUFA probably results in increasing risk of coronary artery disease in populations where this increased risk cannot be explained by conventional risk factors ${ }^{202}$. A randomised single-blind trial in patients with high risk of coronary artery disease, investigated the cardioprotective effects of an IndoMediterranean diet rich in ALA (grains, fruit, walnuts, almonds, soybean oil) compared to the Step I National Education Program prudent diet (total fat $<30 \%$ TEI, $\mathrm{SFA}<10 \% \mathrm{TEI}$, dietary cholesterol $<300 \mathrm{mg} /$ day). It was shown that the Indo-Mediterranean diet protected from 
total cardiac endpoints, sudden cardiac death, and non-fatal myocardial infractions, and resulted in reduced serum cholesterol concentration. Greater benefits were noted for patients with pre-existing coronary artery disease ${ }^{202}$.

Surveys in Greenland Inuit showed that the actual number of myocardial infarctions was much lower than the expected number leading to exploration of factors that might be involved ${ }^{203}$. It was found that the traditional Greenland Inuit diet was very rich in fat as well as protein, and particularly rich in LC n-3 PUFA due to high intake of whale and seal meat and fat ${ }^{204}$. It was then proposed that a high intake of LC n-3 PUFA may be protective against cardiovascular mortality related to modification of blood lipid profile, platelet aggregation and blood clotting. Various studies have shown that use of fish oil is advantageous for the prevention of CHD. This is attributed mainly to the antiarrhythmic and antithrombotic effects of LC n-3 PUFA (ref. ${ }^{183}$ ), combined with normalisation of endothelial dysfunction and blood lipid profile. According to the American Hearth Association, the recommended daily dose of LC n-3 PUFA in secondary prevention of CHD is $1 \mathrm{~g}$ EPA and DHA.

According to the findings of the GISSI Prevenzione Trial $^{29,205}$, supplementation for 3.5 years with LC n-3 PUFA (1g/day) versus placebo to patients surviving a recent myocardial infraction, resulted in relative risk reduction for cardiovascular, coronary, and sudden death $(30-45 \%)\left(\right.$ ref. $\left.^{200}\right)$. It has also been shown that fish oil supplementation in patients awaiting carotid endarterectomy (1.4 g EPA plus DHA/day) resulted in increased LC n-3 PUFA incorporation in atherosclerotic plaques and it was associated with a decreased number of macrophages and increased plaque stability ${ }^{206}$. In relation to these findings, consumption of fish and vegetable oils has been shown to be protective, whereas consumption of full fat dairy products and hydrogenated fat has been associated with increased risk of coronary artery disease ${ }^{207}$. Also, habitual high fish consumption in Japan has been associated with lower risk of hypercholesterolemia and lower risk of CHD (ref. ${ }^{208}$ ).

Apart from the antiarrhythmic and antithrombotic effects of LC n-3 PUFA, their antiinflammatory effect is very important since inflammation is a substantial component of CVD ( ref. $^{23}$ ). Eicosanoid production is affected by fatty acid status. It has been shown that supplementation with LC n-3 PUFA results in higher levels of EPA and DHA in plasma and mononuclear cells and lower levels of AA ( ref. $^{22}$ ). This has been related to inhibition of AA-derived lipid mediator production, and higher production of less inflammatory potent eicosanoids, resolvins, docosatrienes derived from EPA and DHA (ref. ${ }^{209}$ ). Also, supplementation with fish oil has resulted in lower cytokine production (IL-1, IL-6, TNF- $\alpha$ ) and T-lymphocyte proliferation $^{210}$, predisposing to a less inflammatory environment which may enhance the cardioprotective properties of LC n-3 PUFA (ref. ${ }^{211}$ ).

The TAG-lowering effect of LC n-3 PUFA has been well demonstrated, however, the magnitude of the effect varies depending on the dose of supplementation ${ }^{212,213}$. At present, n-3 PUFA ethyl esters are registered for treatment of dyslipidemia in several countries (e.g. USA, Austria). It should be stressed that the dose of n-3 PUFA necessary for the induction of gene expression is 3-5 times higher than the dose for EFA deficiency prevention. Polyunsaturated FAs are used also as combination therapy with fibrates, statins or nicotinic acid, when monotherapy is not successful. It has been shown that in patients with severe hypertriacyglycerolemia, mainly Type V hyperlipoproteinemia (increased chylomicrons and VLDL), the combination of bezafibrate and n-3 PUFA supplementation resulted in marked decrease of TAG. The effect of fibrates and n-3 PUFA is additive in lowering TAG concentrations ${ }^{214}$. In patients with diabetic dyslipidemia treated with statin-fibrate combination, supplementation with n-3 PUFA further decreased plasma TAG, total homocysteine and microalbuminuria ${ }^{215}$. A randomised double-blind trial in CHD patients receiving either statins or fibrates showed that lipid lowering drugs affect EFA metabolism. In both treatment groups, AA levels were increased and LA levels were decreased. Also, ALA and DHA decreased only in the fibrate treatment group. These results have raised questions over whether a diet low in n-6 PUFA and high in n-3 PUFA may ameliorate drug effectiveness ${ }^{216}$. A systematic review of randomised controlled trials showed that among antilipidemic agents and diet, statins and n-3 PUFA are the most protective against overall and cardiac mortality. It was shown that n-3 PUFA alone decreased total mortality by $23 \%$ and cardiac mortality by $32 \%$ (ref. $^{217}$ ).

\section{Insulin sensitivity and the metabolic syndrome}

Dietary fat affects insulin sensitivity and secretion ${ }^{218}$. Insulin release from $\beta$-cells of Langerhan's islets is upregulated during acute increased exposure to FA (specifically 18:0). However, the effect of FA on insulin release is inhibitory during long-term increased levels of FA which deteriorate insulin resistance. Also, the effect of FA on insulin secretion is influenced by their chain length and degree of unsaturation ${ }^{219}$. Insulin release is enhanced more by SFA than PUFA. The mechanism of this $\beta$-cell response is not known, although it has been suggested that an unknown FA metabolite (receptor) resulting from insulin action through SREBP-1c is involved ${ }^{220}$. A study showed that postprandial $\beta$-cell function and insulin sensitivity improved with increased proportion of MFA to SFA in dietary fat ${ }^{221}$. Also, population studies have shown a favourable relationship between MFA intake and $\beta$-cell insulin secretion ${ }^{222}$.

Mice studies have shown that high fat diets promote hyperglycemia, insulin resistance, and non-alcoholic fatty liver disease. These effects are associated with suppressed expression of enzymes involved in PUFA synthesis and decreased LC n-3 PUFA content in the liver. Insulin promotes gene expression of the glycolytic enzyme L-pyruvate kinase, while n-3 PUFA suppress its expression ${ }^{33,34}$.

High intake of dietary fat in humans has been associated with increased risk of obesity, Type 2 diabetes and the metabolic syndrome ${ }^{223}$. Even in developing countries where nutrition transition takes place, there are indications that increased intake of SFA and n-6 PUFA, and 
decreased intake of MFA and n-3 PUFA may contribute to the development of these diseases ${ }^{3}$.

In the treatment of the metabolic syndrome, LC n-3 PUFA, apart from having beneficial effects on the cardiovascular and hemodynamic components, they may also affect insulin sensitivity, however, the existing evidence is inconclusive ${ }^{224}$. A randomised cross-over dietary intervention in young iron-deficient women examined the consumption of either 4 portions of oily fish or red meat per week. It was shown that in the oily fish group insulin sensitivity was improved ${ }^{225}$. Fish oil supplementation studies in overweight and/or hypertensive individuals have also shown improvement of glucose-insulin metabolism ${ }^{226,227}$.

\section{Critically ill patients, cancer and other chronic diseases}

Increased fat consumption has been associated with the development of specific types of cancer such as breast, colonic and pancreatic cancer ${ }^{228}$. Although the amount of total fat is important, it has been shown that the type of fat also plays a significant role ${ }^{229}$. Saturated FA and MFA have been shown to have only a weak effect on promoting tumours. In contrast, n-6 PUFA have been associated with a greater capacity to induce tumour formation ${ }^{230}$. However, epidemiological studies show that SFA and animal fat increase the risk of colon and breast cancer ${ }^{231}$. Long chain n-3 PUFA have been shown to have inhibitory effects in tumour formation, probably through alteration of PG synthesis and inhibition of cell proliferation in colon and breast cancer ${ }^{230}$. As the Western diet contains disproportionally high amounts of n-6 PUFA and low amounts of n-3 PUFA, the resulting high n-6/n-3 PUFA ratio is thought to contribute to cancer ${ }^{232}$.

Population based studies have shown that high intake of fat, particularly that of SFA, has been associated with increased risk of pancreatic cancer ${ }^{233-235}$. Evidence shows that fish oil supplementation may prevent cachexia in pancreatic cancer patients ${ }^{236}$. Epidemiological data show that high intake of LC n-3 PUFA $(\geq 0.85 \mathrm{~g} /$ day $)$ is associated with lower risk of developing pancreatic cancer (odds ratio, 0.47) (ref. ${ }^{237}$ ). It has been demonstrated that the effect of LC n-3 PUFA on pancreatic function may be mediated by inhibition of PG and pro-inflammatory cytokine synthesis ${ }^{238,239}$. Particularly, the anticarcinogenic properties of LC n-3 PUFA, which are mainly attributed to altered $\mathrm{PG}$ formation due to COX-2 inhibition, may prove beneficial in pancreatic cancer ${ }^{240}$. Fish oil in total parenteral nutrition improved patient recovery and indices of pancreatic and hepatic function in postoperative cancer patients $^{231,241}$.

After elective surgery for cancer, enteral nutrition supplemented with LC n-3 PUFA resulted in reduction of gastrointestinal complications and infections by $50 \%$ (ref. ${ }^{242,243}$ ). Enteral nutrition enriched with EPA in critically ill patients with Adult Respiratory Distress Syndrome (ARDS) has been associated with decreased infiltration of neutrophils in the lungs, improved respiration, and shorter hospitalisation in intensive care unit (ICU). Treatment with LC n-3 PUFA seems to be effective in preventing disseminated intravascular coagulation and ARDS. Lipid emulsions used in parenteral nutrition prevent low energy intake but also improve outcome by modulation of oxidative stress and inflammation. Recently developed lipid emulsions have substituted soybean oil with oils rich in medium chain triacylglycerols (MCT), n-9 MFA (ref. ${ }^{244}$ ) and n-3 PUFA (ref. ${ }^{245,246}$ ). A decreased state of PUFA in lipids of septic patients has been documented and this may be linked to increased severity of their critical condition $^{247}$. A randomised controlled study of fish oil in parenteral nutrition of septic ICU patients showed that fish oil modified inflammatory cytokine production and was associated with shorter hospitalisation ${ }^{248}$.

Isolated ethyl esters of DHA may improve clinical and biochemical parameters in children with disorders of peroxisome biogenesis (Zellweger syndrome, neonatal adrenoleukodystrophy, infantile Refsum's disease) (ref. ${ }^{187,249}$ ). Enteral supplementation with lipid emulsion containing LC n-3 PUFA and MCT had beneficial effects in patients with chylomicronemic syndrome combined with severe acute pancreatitis.

Fatty acids are also important in protein-energy malnutrition. Losses of skeletal muscle in some types of proteinenergy malnutrition are associated with enhanced protein catabolism due to the effect of TNF- $\alpha$, glucocorticoids and proteolysis inducing factor (PIF) on skeletal muscle proteins. Supplementation with EPA was shown to attenuate degradation of skeletal muscles probably by inhibition of PIF. In experimental models, EPA inhibited proteasome activity by reducing its expression ${ }^{250,251}$.

\section{Immune system disorders}

Fatty acids have been shown to affect inflammatory processes and, thus, diseases with an inflammatory component $^{24}$. Chronic inflammatory conditions that are related to Th1 response dysregulation are characterised by inappropriate production of AA-derived eicosanoids (PGE2 and LTB4) and inflammatory cytokines. Since n-3 PUFA from fish oil act to decrease AA-derived eicosanoid production, it has been suggested that fish oil may have a preventive or therapeutic role for these diseases ${ }^{23}$. Supplementation trials have been conducted for most of these diseases. Clinical trials provide good evidence of the antiinflammatory and clinical improvement effects of fish oil on rheumatoid arthritis ${ }^{252-254}$ and inflammatory bowel diseases (Crohn's disease and ulcerative colitis) (ref. ${ }^{255,256}$ ). However, the therapeutic effect of fish oil on other conditions, such as multiple sclerosis and systemic lupus erythematosus, is not clearly evident ${ }^{257-259}$. Polymorphisms in the cluster of chromosome 11 that encodes $\Delta 5$ - and $\Delta 6$-desaturases (11q12-11q13.1) have been associated with asthma, atopy, osteoarthritis, bipolar disorder, and Type 1 diabetes ${ }^{172}$.

Immune disorders characterised by polarisation towards T-helper type 2 (Th2) responses (mainly IL-5 and IL-4 secretion), such as atopy (allergies, eczema, asthma, hay-fever), may also be influenced by the type of dietary fat ingested. The hypothesis that has evolved is that an increased intake of n-6 PUFA accompanied by a low intake of n-3 PUFA has played a causal role in increased asthma incidence in the last 30 to 40 years ${ }^{260,261}$. Atopic diseases are associated with production of AA-derived 
eicosanoids such as PGD2, LTC4, LTD4 and LTE4. Also, PGE2 regulates the activities of macrophages and lymphocytes, inhibits the production of Th1-type cytokines (interferon (IFN)- $\gamma$, IL-2), regulates T-cell lymphocyte differentiation promoting the development of a Th2 phenotype ${ }^{262}$, and stimulates B-cells to produce immunoglobulin $\mathrm{E}(\mathrm{IgE})\left(\right.$ ref. $\left.^{263}\right)$. The protective effect of early perinatal exposure to marine LC n-3 PUFA against atopy development in the offspring has been demontrated ${ }^{118,119}$. Also, a number of studies have been conducted investigating the possible therapeutic affects of fish oil on asthmatic adult patients. It has been reported that fish oil supplementation in patients with asthma has antiinflammatory effects $^{264-266}$. Also, fish oil trials have shown beneficial effects on asthma clinical outcomes ${ }^{267}$. However, reviews on this field ${ }^{267,268}$ concluded that the evidence is inconsistent and that further studies are needed in order to provide strong evidence of the potent therapeutic effects of fish oil on asthma.

\section{CONCLUSION}

The importance of FAs as biocompounds can be demonstrated by their physiological roles, including lipid mediator production and involvement in gene expression. Although existing dietary reference values for fat intake vary between different nutrition bodies, all of them agree on a maximum intake of total fat of $30-35 \%$ TEI, a low intake of SFA and a higher intake of MFA. Regarding PUFA, it is essential to decrease n-6 PUFA and increase LC n-3 PUFA intake through oily fish consumption (1-2 portions/week). Public health policies promoting oily fish consumption should be formulated to ensure maternal intake of at least 250-300 mg DHA/day. Increased intake of LC n-3 PUFA should also be promoted as secondary prevention of CHD because of their cardioprotective and antiinflammatory properties. Saturated FA and trans FA have a negative effect on CVD and metabolic disorders, whereas MFA may have a protective role. The beneficial effect of LC n-3 PUFA and the negative effect of SFA have been demonstrated in some types of cancer (pancreatic, breast, colon), but it should be further investigated in other types of cancer and in different stages. Critically ill patients and those suffering from chronic immune system disorders may benefit from decreased intake of $n-6$ and increased intake of n-3 PUFA. The effects of different types of fat on various conditions (pancreatic and liver function, cancer, asthma, mental health, growth and development) should be further investigated taking into account diet-gene interactions. This underlines the importance of nutrigenomics and environmental modifications for sustainable health and disease outcome.

\section{ABBREVIATIONS}

7-TM, 7-Tansmembrane- helix; AA, Arachidonic acid; AI, Adequate intake; ALA, $\alpha$-Linolenic acid; AP, Activation protein; ARDS, Adult respiratory dis- tress syndrome; $\mathrm{CB}$, Cannabinoid receptor/s; CE, Cholesteryl ester/s; CETP, Cholesteryl ester transfer protein; CHD, Coronary heart disease; ChREBP/ MLX, Carbohydrate regulatory element binding protein/Max-like factor X; CLA, Conjugated linoleic acid; COX, Cyclooxygenase/s; CVD, Cardiovascular disease; DG, Diacylglycerol/s; DGLA, Dihomo- $\gamma$-linolenic acid; DHA, Docosahexaenoic acid; DPA, Docosapentaenoic acid; DRV, Dietary reference value/s; EFA, Essential fatty acid/s; EFSA, European food safety authority; EPA, Eicosapentaenoic acid; FA, Fatty acid/s; FADS, Fatty acid desaturase/s; FEN, Flapstructure specific endonuclease/s; GLP, Glucagon-like peptide; HDL, High density lipoprotein; HEPE, Hydroxyeicosapentaenoic acid; HETE, Hydroxyeicosatetraenoic acid; HNF, Hepatic nuclear factor; HODE, Hydroxyoctadecanoic acid; HPEPE, Hydroperoxyeicosapentaenoic acid; HPETE, Hydroperoxyeicosatetraenoic acid; HPODE, Hydroperoxyoctadecanoic acid; ICAM-I, Intercellular adhesion molecule-I; ICU, Intensive care unit; IFN- $\gamma$, Interferon- $\gamma$; IL, Interleukin; $\mathrm{IP}_{3}$, Inositol-triphosphate; LA, Linoleic acid; LC, Long chain; LDL, Low density lipoprotein; LOX, Lipoxygenase/s; LPC, Lysophosphatidylcholine; LPL, Lipoprotein lipase/s; LT, Leukotriene/s; LX, Lipoxin/s; LXR, Liver X receptor; MaR, Maresin/s; MCT, Medium chain triacylglycerol/s; MFA, Monounsaturated fatty acid/s; MTP, Microsomal triacylglycerol transfer protein; NADPH, Nicotinamide adenine dinucleotide phosphate (reduced form); NDA, Panel on Dietetic Products, Nutrition, and Allergies; NEFA, Non-esterified fatty acid/s; NFkB, Nuclear factor kappa B; NP, Neuroprotectin; NSAID, Non-steroidal antiinflammatory drugs; OXO, Oxooctadecadienoic acid; PA, Phosphatidic acid; PAF, Platelet activating factor; PC, Phosphatidylcholine; PG, Prostaglandin/s; PI, Phosphatidylinositol; PIF, Proteolysis inducing factor; PIP2, Phosphatidylinositol-bisphosphate; PKC, Protein kinase C; PL, Phospholipase/s; PPAR: peroxisome proliferator-activated receptor/s; PPRE, Peroxisome proliferator-response element/s; PUFA, Polyunsaturated fatty acid/s; RONS, Reactive oxygen and nitrogen species; Rv, Resolvin/s; RXR, Retinoid-X-receptor; SFA, Saturated fatty acid/s; SNP, Single nucleotide polymorphism/s; SPM, Specialised pro-resolving mediator; SREBP, Sterol regulatory element binding protein/s; TAG, Triacylglycerol/s; TEI, Total energy intake; Th1/2, T-helper type 1/2; TLC, Therapeutic lifestyle changes; TNF- $\alpha$, Tumor necrosis factor- $\alpha$; TX, Thromboxane; U-AMDR, Upper level of acceptable macronutrient distribution range; VCAM-I, Vascular cell adhesion molecule-I; VLCFA, Very long chain fatty acid/s; VLDL, Very low density lipoprotein.

\section{ACKNOWLEDGEMENT}

This work is supported by the research project of the Ministry of Education, Youth and Sport (Czech Republic, MSM 0021620820 and MSM 0021620807). 


\section{REFERENCES}

1. Crovetto M, Uauy R. Changes in household food and nutrient consumption in Metropolitan Santiago 1988-97 by income. Rev Med Chil 2010;138:1091-108.

2. Austin GL, Ogden LG, Hill JO. Trends in carbohydrate, fat, and protein intakes and association with energy intake in normalweight, overweight, and obese individuals: 1971-2006. Am J Clin Nutr 2011; Epub ahead of print: (doi)10.3945/ajen.110.000141.

3. Misra A, Singhal N, Khurana L. Obesity, the metabolic syndrome, and type 2 diabetes in developing countries: role of dietary fats and oils. J Am Coll Nutr 2010;29:289S-301S.

4. Tvrzicka E, Kremmyda L-S, Stankova B, Zak A. Fatty acids as biocompounds: Their role in human metabolism, health and disease - A review. Part 1: classification, dietary sources and biological functions. Biomed Pap 2011;155:117-30.

5. Brenna JT, Salem N, Jr., Sinclair AJ, Cunnane SC. $\alpha$-Linolenic acid supplementation and conversion to n-3 long-chain polyunsaturated fatty acids in humans. Prostaglandins Leukot Essent Fatty Acids 2009;80:85-91.

6. Lattka E, Illig T, Koletzko B, Heinrich J. Genetic variants of the FADS1 FADS2 gene cluster as related to essential fatty acid metabolism. Curr Opin Lipidol 2010;21:64-9.

7. Merino DM, Ma DW, Mutch DM. Genetic variation in lipid desaturases and its impact on the development of human disease. Lipids Health Dis 2010;9:63.

8. EFSA Panel on Dietetic Products, Nutrition and Allergens (NDA) Scientific Opinion on Dietary Reference Values for fats, including saturated fatty acids, polyunsaturated fatty acids, monounsaturated fatty acids, trans fatty acids, and cholesterol. EFSA Journal 2010;8:1461.

9. Nelson DL, Cox MM. Lipid Biosynthesis. In: Principles of Biochemistry. New York: W.H. Freeman and Company; 2005. p. 787-815.

10. Nelson DL, Cox MM. Lipids. In: Principles of Biochemistry. New York: W.H. Freeman and Company; 2005. p. 343-63.

11. Havel RJ, Eder HA, Bragdon JH. The distribution and chemical composition of ultracentrifugally separated lipoproteins in human serum. J Clin Invest 1955;34:1345-53.

12. Fukami K, Inanobe S, Kanemaru K, Nakamura Y. Phospholipase $\mathrm{C}$ is a key enzyme regulating intracellular calcium and modulating the phosphoinositide balance. Prog Lipid Res 2010;49:429-37.

13. Nishizuka Y. Membrane phospholipid degradation and protein kinase C for cell signalling. Neurosci Res 1992;15:3-5.

14. Smith WL. Nutritionally essential fatty acids and biologically indispensable cyclooxygenases. Trends Biochem Sci 2008;33:27-37.

15. Serhan CN, Arita M, Hong S, Gotlinger K. Resolvins, docosatrienes, and neuroprotectins, novel omega-3-derived mediators, and their endogenous aspirin-triggered epimers. Lipids 2004;39:112532 .

16. Serhan CN. Novel eicosanoid and docosanoid mediators: resolvins, docosatrienes, and neuroprotectins. Curr Opin Clin Nutr Metab Care 2005;8:115-21.

17. Bazan NG. Neuroprotectin D1 (NPD1): a DHA-derived mediator that protects brain and retina against cell injury-induced oxidative stress. Brain Pathol 2005;15:159-66.

18. Bazan NG, Calandria JM, Serhan CN. Rescue and repair during photoreceptor cell renewal mediated by docosahexaenoic acidderived neuroprotectin D1. J Lipid Res 2010;51:2018-31.

19. Oh SF, Pillai PS, Recchiuti A, Yang R, Serhan CN. Pro-resolving actions and stereoselective biosynthesis of $18 \mathrm{~S}$ E-series resolvins in human leukocytes and murine inflammation. J Clin Invest 2011;121:569-81.

20. Bannenberg G, Serhan CN. Specialized pro-resolving lipid mediators in the inflammatory response: An update. Biochim Biophys Acta 2010;1801:1260-73.

21. Berdyshev EV, Boichot E, Lagente V. Anandamide-a new look on fatty acid ethanolamides. J Lipid Mediat Cell Signal 1996;15:49-67.

22. Calder PC. Immunomodulation by omega-3 fatty acids. Prostaglandins Leukot Essent Fatty Acids 2007;77:327-35.
23. Calder PC. N-3 polyunsaturated fatty acids and inflammation: from molecular biology to the clinic. Lipids 2003;38:343-52.

24. Simopoulos AP. Omega-3 fatty acids in inflammation and autoimmune diseases. J Am Coll Nutr 2002;21:495-505.

25. Calder PC, Yaqoob P. Omega-3 polyunsaturated fatty acids and human health outcomes. Biofactors 2009;35:266-72.

26. Haeggstrom JZ, Wetterholm A. Enzymes and receptors in the leukotriene cascade. Cell Mol Life Sci 2002;59:742-53.

27. Pratico D, Lawson JA, Rokach J, FitzGerald GA. The isoprostanes in biology and medicine. Trends Endocrinol Metab 2001;12:243-7.

28. Resh MD. Fatty acylation of proteins: new insights into membrane targeting of myristoylated and palmitoylated proteins. Biochim Biophys Acta 1999;1451:1-16.

29. The GISSI-Prevenzione Investigators. Dietary supplementation with n-3 polyunsaturated fatty acids and vitamin E after myocardial infarction: results of the GISSI-Prevenzione trial. Gruppo Italiano per lo Studio della Sopravvivenza nell'Infarto miocardico. Lancet 1999;354:447-55.

30. Burr ML, Fehily AM, Gilbert JF, Rogers S, Holliday RM, Sweetnam PM, Elwood PC, Deadman NM. Effects of changes in fat, fish, and fibre intakes on death and myocardial reinfarction: diet and reinfarction trial (DART). Lancet 1989;2:757-61.

31. de Lorgeril M, Salen P, Martin JL, Monjaud I, Delaye J, Mamelle N. Mediterranean diet, traditional risk factors, and the rate of cardiovascular complications after myocardial infarction: final report of the Lyon Diet Heart Study. Circulation 1999;99:779-85.

32. Chapkin RS, McMurray DN, Davidson LA, Patil BS, Fan YY, Lupton JR. Bioactive dietary long-chain fatty acids: emerging mechanisms of action. Br J Nutr 2008;100:1152-7.

33. Jump DB. N-3 polyunsaturated fatty acid regulation of hepatic gene transcription. Curr Opin Lipidol 2008;19:242-7.

34. Jump DB. Fatty acid regulation of hepatic lipid metabolism. Curr Opin Clin Nutr Metab Care 2011;14:115-20.

35. Jump DB. Fatty acid regulation of gene transcription. Crit Rev Clin Lab Sci 2004;41:41-78.

36. Lapillonne A, Clarke SD, Heird WC. Polyunsaturated fatty acids and gene expression. Curr Opin Clin Nutr Metab Care 2004;7:1516 .

37. Pertwee RG. Ligands that target cannabinoid receptors in the brain: from THC to anandamide and beyond. Addict Biol 2008;13:147-59.

38. Hannuksela ML, Liisanantti MK, Nissinen AE, Savolainen MJ. Biochemical markers of alcoholism. Clin Chem Lab Med 2007;45:953-61.

39. Chao W, Olson MS. Platelet-activating factor: receptors and signal transduction. Biochem J 1993;292:617-29.

40. Engelstoft MS, Egerod KL, Holst B, Schwartz TW. A gut feeling for obesity: 7TM sensors on enteroendocrine cells. Cell Metab 2008;8:447-9.

41. Samuel BS, Shaito A, Motoike T, Rey FE, Backhed F, Manchester JK, Hammer RE, Williams SC, Crowley J, Yanagisawa M, Gordon JI. Effects of the gut microbiota on host adiposity are modulated by the short-chain fatty-acid binding $G$ protein-coupled receptor, Gpr41. Proc Natl Acad Sci USA 2008;105:16767-72.

42. Reimann F, Habib AM, Tolhurst G, Parker HE, Rogers GJ, Gribble FM. Glucose sensing in L cells: a primary cell study. Cell Metab 2008;8:532-9.

43. Bennett MV, Verselis VK. Biophysics of gap junctions. Semin Cell Biol 1992;3:29-47.

44. Lombardi F, Terranova P. Anti-arrhythmic properties of N-3 polyunsaturated fatty acids (n-3 PUFA). Curr Med Chem 2007;14:207080.

45. D-A-CH (Deutsche Gesellschaft für Ernährung - Österreichische Gesellschaft für Ernährung - Schweizerische Gesellschaft für Ernährungsforschung - Schweizerische Vereinigung für Ernährung). Referenzwerte für die Nährstoffzufuhr. Umschau Braus Verlag, Frankfurt am Main; 2008.

46. NNR (Nordic Nutrition Recommendations). Integrating nutrition and physical activity. Copenhagen: Nordic Council of Ministers; 2004.

47. Department of Health (UK). Dietary Reference Values for Food Energy and Nutrients for the United Kingdom. Report of the Panel 
on Dietary Reference Values of the Committee on Medical Aspects of Food Policy. London: HMSO; 1991.

48. AFSSA (Agence Française de Sécurité Sanitaire des Aliments). Apports nutritionnels conseillés pour la population française. Paris: Editions Tec\&Doc; 2001.

49. GR (Gezondheidsraad). Dietary Reference Intakes: energy, proteins, fats and digestible carbohydrates. The Hague: Health Council of the Netherlands; 2001.

50. HHS/USDA. Dietary Guidelines for Americans. US Department of Health and Human Services/US Department of Agriculture; 2005.

51. WHO/FAO (World Health Organization/Food and Agriculture Organization). Interim Summary of Conclusions and Dietary Recommendations on Total Fat \& Fatty Acids. Geneva: The Joint FAO/WHO Expert Consultation on Fats and Fatty Acids in Human Nutrition; 2008

52. NCEP (National Cholesterol Education Program). Detection, evaluation, and treatment of high blood cholesterol in adults (Adult Treatment Panel III). National Institutes of Health (USA); 2001 Publication No 01-3670

53. Cetin I, Koletzko B. Long-chain omega-3 fatty acid supply in pregnancy and lactation. Curr Opin Clin Nutr Metab Care 2008;11:297302 .

54. Simopoulos AP, Leaf A, Salem NJ. Workshop on the essentiality of and Recommended Dietary Intakes for omega-6 and omega-3 fatty acids. J Am Coll Nutr 1999;18:487-9.

55. Koletzko B, Cetin I, Brenna JT. Dietary fat intakes for pregnant and lactating women. International Society for the Study of Fatty Acids and Lipids Newsletter 2007;14:12-7.

56. SACN (Scientific Advisory Committee on Nutrition, Committee on Toxicity). Advice on fish consumption: benefits and risks. London: The Stationary Office; 2004.

57. NHMRC (National Health and Medical Research Council) Dietary Guidelines for Australian Adults. Canberra; 2003.

58. Smit LA, Mozaffarian D, Willett W. Review of fat and fatty acid requirements and criteria for developing dietary guidelines. Ann Nutr Metab 2009;55:44-55.

59. Elmadfa I, Kornsteiner M. Fats and fatty acid requirements for adults. Ann Nutr Metab 2009;55:56-75.

60. Gluckman PD, Hanson MA, Mitchell MD. Developmental origins of health and disease: reducing the burden of chronic disease in the next generation. Genome Med 2010;2:14.

61. Jackson AA, Burdge GC, Lillycrop KA. Diet, nutrition and modulation of genomic expression in fetal origins of adult disease. World Rev Nutr Diet 2010;101:56-72.

62. Barker DJ. The origins of the developmental origins theory. J Intern Med 2007;261:412-7.

63. Allan K, Kelly FJ, Devereux G. Antioxidants and allergic disease a case of too little or too much? Clin Exp Allergy 2009;40:370-80.

64. Department of Health (UK), Food Standards Agency. Nationa Diet and Nutrition Survey: NDNS Headline results from Year 1 of the Rolling programme (2008/2009). London: The Stationary Office; 2009.

65. Shaheen SO, Newson RB, Henderson AJ, Emmett PM, Sherriff A, Cooke M. Umbilical cord trace elements and minerals and risk of early childhood wheezing and eczema. Eur Respir J 2004;24:292-7.

66. Jennings S, Prescott SL. Early dietary exposures and feeding practices: role in pathogenesis and prevention of allergic disease? Postgrad Med J 2010;86:99.

67. Prescott SL, Dunstan JA. Prenatal fatty acid status and immune development: The pathways and the evidence. Lipids 2007;42:80110.

68. Herrera E. Metabolic adaptations in pregnancy and their implications for the availability of substrates to the fetus. Eur J Clin Nutr 2000;54:S47-S51.

69. Herrera E, Lopez-Soldado I, Limones M, Amusquivar E, Ramos MP. Lipid metabolism during the perinatal phase, and its implications on postnatal development. Int J Vit Nutr Res 2006;76:216-24.

70. Herrera E. Lipid metabolism in pregnancy and its consequences in the fetus and newborn. Endocrine 2002;19:43-55.
71. Haggarty P. Effect of placental function in fatty acid requirements during pregnancy. Eur J Clin Nutr 2004;58:1559-70.

72. Klingler M, Demmelmair H, Larque E, Koletzko B. Analysis of FA contents in individual lipid fractions from human placental tissue. Lipids 2003;38:561-6.

73. Herrera E, Amusquivar E, Lopez-Soldado I, Ortega H. Maternal lipid metabolism and placental lipid transfer. Horm Res 2006;65:S59-S64.

74. Hanebutt FL, Demmelmair H, Schiessl B, Larque E, Koletzko B. Long-chain polyunsaturated fatty acid (LC-PUFA) transfer across the placenta. Clin Nutr 2008;27:685-93.

75. Bitsanis D, Crawford MA, Moodley T, Holmsen H, Ghebremeskel $\mathrm{K}$, Djahanbakhch O. Arachidonic acid predominates in the membrane phosphoglycerides of the early and term human placenta. $\mathbf{J}$ Nutr 2005;135:2566-71.

76. Khan AH, Carson RJ, Nelson SM. Prostaglandins in labor-a translational approach. Front Biosci 2008;13:5794-809.

77. Berghaus TM, Demmelmair H, Koletzko B. Fatty acid composition of lipid classes in maternal and cord plasma at birth. Eur J Pediatr 1998; 157:763-8.

78. De Vriese SR, Dhont M, Christophe AB. FA composition of cholesteryl esters and phospholipids in maternal plasma during pregnancy and at delivery and in cord plasma at birth. Lipids 2003;38:1-7.

79. Min Y, Ghebremeskel K, Crawford MA, Nam JH, Kim A, Koo JN, Suzuki H. Pregnancy reduces arachidonic and docosahexaenoic in plasma triacylglycerols of Korean women. Int J Vit Nutr Res 2000;70:70-5.

80. Vlaardingerbroek H, Hornstra G. Essential fatty acids in erythrocyte phospholipids during pregnancy and at delivery in mothers and their neonates: Comparison with plasma phospholipids. Prostaglandins Leukot Essent Fatty Acids 2004;71:363-74.

81. Houwelingen ACV, Foreman V, Nicolini U, Nicolaides $\mathrm{KH}, \mathrm{Al}$ MDM, Kester ADM, Hornstra G. Essential fatty acid status of fetal plasma phospholipids: Similar to postnatal values obtained at comparable gestational ages. Early Hum Dev 1996;46:141-52.

82. De Vriese SR, Matthys C, De HS, De BG, Dhont M, Christophe AB. Maternal and umbilical fatty acid status in relation to maternal diet. Prostaglandins Leukot Essent Fatty Acids 2002;67:389-96.

83. Donahue SMA, Rifas-Shiman SL, Olsen SF, Gold DR, Gillman MW, Oken E. Associations of maternal prenatal dietary intake of n-3 and n-6 fatty acids with maternal and umbilical cord blood levels. Prostaglandins Leukot Essent Fatty Acids 2009;80:289-96.

84. Hornstra G. Essential fatty acids in mothers and their neonates. Am J Clin Nutr 2000;71:1262S-9S.

85. Houwelingen AC, Ham ECH, Hornstra G. The female docosahexaenoic acid status related to the number of completed pregnancies. Lipids 1999;34:S229.

86. Bo S, Menato G, Lezo A, Signorile A, Bardelli C, De MF, Massobrio M, Pagano G. Dietary fat and gestational hyperglycaemia. Diabetologia 2001;44:972-8.

87. Oken E, Ning Y, Rifas-Shiman SL, Rich-Edwards JW, Olsen SF, Gillman MW. Diet during pregnancy and risk of preeclampsia or gestational hypertension. Ann Epidemiol 2007;17:663-8.

88. Al MDM, van Houwelingen AC, Hornstra G. Long-chain polyunsaturated fatty acids, pregnancy, and pregnancy outcome. Am J Clin Nutr 2000;71:285S-91S.

89. Dunstan JA, Simmer K, Dixon G, Prescott SL. Cognitive assessment of children at age 2(1/2) years after maternal fish oil supplementation in pregnancy: a randomised controlled trial. Arch Dis Child Fetal Neonatal Ed 2008;93:F45-F50.

90. Oken E, Kleinman KP, Olsen SF, Rich-Edwards JW, Gillman MW. Associations of seafood and elongated n-3 fatty acid intake with fetal growth and length of gestation: results from a US pregnancy cohort. Am J Epidemiol 2004;160:774-83.

91. Olsen SF, Hansen HS, Sorensen TI, Jensen B, Secher NJ, Sommer $\mathrm{S}$, Knudsen LB. Intake of marine fat, rich in (n-3)-polyunsaturated fatty acids, may increase birthweight by prolonging gestation. Lancet 1986;2:367-9.

92. Olsen SF, Secher NJ. Low consumption of seafood in early pregnancy as a risk factor for preterm delivery: prospective cohort study. BMJ 2002;324:447. 
93. Olsen SF, Osterdal ML, Salvig JD, Weber T, Tabor A, Secher NJ. Duration of pregnancy in relation to fish oil supplementation and habitual fish intake: a randomised clinical trial with fish oil. Eur J Clin Nutr 2007;61:976-85.

94. Olsen SF, Secher NJ, Tabor A, Weber T, Walker JJ, Gluud C. Randomised clinical trials of fish oil supplementation in high risk pregnancies. Fish Oil Trials In Pregnancy (FOTIP) Team. BJOG 2000; 107:382-95.

95. Dirix CE, Kester AD, Hornstra G. Associations between neonatal birth dimensions and maternal essential and trans fatty acid contents during pregnancy and at delivery. Br J Nutr 2009; 101:399. 407.

96. Horvath A, Koletzko B, Szajewska H. Effect of supplementation of women in high-risk pregnancies with long-chain polyunsaturated fatty acids on pregnancy outcomes and growth measures at birth: a meta-analysis of randomized controlled trials. Br J Nutr 2007;98:253-9.

97. Szajewska H, Horvath A, Koletzko B. Effect of n-3 long-chain polyunsaturated fatty acid supplementation of women with lowrisk pregnancies on pregnancy outcomes and growth measures at birth: a meta-analysis of randomized controlled trials. Am J Clin Nutr 2006;83:1337-44.

98. Makrides M, Duley L, Olsen SF. Marine oil, and other prostaglandin precursor, supplementation for pregnancy uncomplicated by pre-eclampsia or intrauterine growth restriction. Cochrane Database Syst Rev 2006;3:CD003402.

99. Innis SM. Dietary omega 3 fatty acids and the developing brain. Brain Res 2008;1237:35-43.

100. Innis SM. Essential fatty acids in growth and development. Prog Lipid Res 1991;30:39-103.

101. Crawford MA, Hassam AG, Williams G. Essential fatty acids and fetal brain growth. Lancet 1976;1:452-3.

102. Koletzko B, Rodriguez-Palmero M. Polyunsaturated fatty acids in human milk and their role in early infant developement. J Mammary Gland Biol Neoplasia 1999;4:269-84.

103. Krauss-Etschmann S, Shadid R, Campoy C, Hoster E, Demmelmair H, Jimenez M, Gil A, Rivero M, Veszpremi B, Decsi T, Koletzko BV. Effects of fish-oil and folate supplementation of pregnant women on maternal and fetal plasma concentrations of docosahexaenoic acid and eicosapentaenoic acid: A European randomized multicenter trial. Am J CLin Nutr 2007;85:1392-400.

104. Houwelingen AC, Sorensen JD, Hornstra G, Simonis MMG Boris J, Olsen SF, Secher NJ. Essential fatty acid status in neonates after fish-oil supplementation during late pregnancy. $\mathrm{Br} \mathrm{J}$ Nutr 1995;74:723-31.

105. Malcolm CA, McCulloch DL, Montgomery C, Shepherd A, Weaver LT. Maternal docosahexaenoic acid supplementation during pregnancy and visual evoked potential development in term infants: a double blind, prospective, randomised trial. Arch Dis Child Fetal Neonatal Ed 2003;88:F383-F390.

106. Judge MP, Harel O, Lammi-Keefe CJ. Maternal consumption of a docosahexaenoic acid-containing functional food during pregnancy: benefit for infant performance on problem-solving but not on recognition memory tasks at age 9 mo. Am J Clin Nutr 2007; 85:1572-7.

107. Gibson RA, Neumann MA, Makrides M. Effect of increasing breast milk docosahexaenoic acid on plasma and erythrocyte phospholipid fatty acids and neural indices of exclusively breast fed infants. Eur J Clin Nutr 1997;51:578-84.

108. Jensen CL, Voigt RG, Llorente AM, Peters SU, Prager TC, Zou YL, Rozelle JC, Turcich MR, Fraley JK, Anderson RE, Heird WC. Effects of early maternal docosahexaenoic acid intake on neuropsychological status and visual acuity at five years of age of breast-fed term infants. J Pediatr 2010;157:900-5.

109. Lauritzen L, Jorgensen MH, Olsen SF, Straarup EM, Michaelsen KF. Maternal fish oil supplementation in lactation: Effect on developmental outcome in breast-fed infants. Reprod Nutr Dev 2005;45:535-47.

110. Lauritzen L, Jorgensen MH, Mikkelsen TB, Skovgaard IM, Straarup E-M, Olsen SF, Hoy C-E, Michaelsen KF. Maternal fish oil supplementation in lactation: Effect on visual acuity and omega- 3 fatty acid content of infant erythrocytes. Lipids 2004;39:195-206.

111. Helland IB, Smith L, Saarem K, Saugstad OD, Drevon CA. Maternal supplementation with very-long-chain n-3 fatty acids during pregnancy and lactation augments children's IQ at 4 years of age. Pediatrics 2003;111:E39-E44.

112. Helland IB, Smith L, Blomen B, Saarem K, Saugstad OD, Drevon CA. Effect of supplementing pregnant and lactating mothers with $\mathrm{n}-3$ very-long-chain fatty acids on children's IQ and body mass index at 7 years of age. Pediatrics 2008;122:E472-E479.

113. Brenna JT, Lapillonne A. Background paper on fat and fatty acid requirements during pregnancy and lactation. Ann Nutr Metab 2009;55:97-122.

114. Lauritzen L, Kjaer TM, Porsgaard T, Fruekilde MB, Mu H, Frokiaer H. Maternal Intake of Fish Oil but not of Linseed Oil Reduces the Antibody Response in Neonatal Mice. Lipids 2011;46:171-8.

115. Oddy WH, Pal S, Kusel MMH, Vine D, De Klerk NH, Hartmann P, Holt PG, Sly PD, Burton PR, Stanley FJ, Landau LI. Atopy, eczema and breast milk fatty acids in a high-risk cohort of children followed from birth to 5 years. Pediatr Allergy Immunol 2006;17:4-10.

116. Stoney RM, Woods RK, Hosking CS, Hill DJ, Abramson MJ, Thien FCK. Maternal breast milk long-chain omega-3 fatty acids are associated with increased risk of atopy in breastfed infants. Clin Exp Allergy 2004;34:194-200.

117. Calder PC. Early life programming of immune and lung function: can we now exclude a role of arachidonic acid exposure? Br J Nutr 2009; 102:331-3

118. Calder PC, Kremmyda LS, Vlachava M, Noakes PS, Miles EA. Is there a role for fatty acids in early life programming of the immune system? Proc Nutr Soc 2010;69:373-80.

119. Kremmyda LS, Vlachava M, Noakes PS, Diaper ND, Miles EA, Calder PC. Atopy Risk in Infants and Children in Relation to Early Exposure to Fish, Oily Fish, or Long-Chain Omega-3 Fatty Acids: A Systematic Review. Clin Rev Allergy Immunol 2009; Epub ahead of print: (doi) 10.1007/s12016-009-8186-2.

120. Dunstan JA, Mori TA, Barden A, Beilin LJ, Taylor AL, Holt PG, Prescott SL. Fish oil supplementation in pregnancy modifies neonatal allergen-specific immune responses and clinical outcomes in infants at high risk of atopy: A randomized, controlled trial. J Allergy Clin Immunol 2003;112:1178-84.

121. Furuhjelm C, Warstedt K, Larsson J, Fredriksson M, Fageras Bottcher M, Falth-Magnusson K, Duchen K. Fish oil supplementation in pregnancy and lactation may decrease the risk of infant allergy. Acta Paediatr 2009;98:1461-7.

122. Lauritzen L, Hoppe C, Straarup EM, Michaelsen KF. Maternal fish oil supplementation in lactation and growth during the first 2.5 years of life. Pediatr Res 2005;58:235-42.

123. Warstedt K, Furuhjelm C, Duchen K, Falth-Magnusson K, Fageras M. The effects of omega-3 fatty acid supplementation in pregnancy on maternal eicosanoid, cytokine, and chemokine secretion. Pediatr Res 2009;2:212-7.

124. Noakes PS, Hale J, Thomas R, Lane C, Devadason SG, Prescott SL. Maternal smoking is associated with impaired neonatal toll-like-receptor-mediated immune responses. Eur Respir J 2006;28:721-9.

125. Noakes PS, Taylor P, Wilkinson S, Prescott SL. The relationship between persistent organic pollutants in maternal and neonatal tissues and immune responses to allergens: A novel exploratory study. Chemosphere 2006;63:1304-11.

126. Dunstan JA, Mitoulas LR, Dixon G, Doherty DA, Hartmann PE, Simmer K, Prescott SL. The effects of fish oil supplementation in pregnancy on breast milk fatty acid composition over the course of lactation: a randomized controlled trial. Pediatr Res 2007;62:689-94

127. Bergmann RL, Haschke-Becher E, Klassen-Wigger P, Bergmann KE, Richter R, Dudenhausen JW, Grathwohl D, Haschke F. Supplementation with $200 \mathrm{mg} /$ day docosahexaenoic acid from mid-pregnancy through lactation improves the docosahexaenoic acid status of mothers with a habitually low fish intake and of their infants. Ann Nutr Metab 2008;52:157-66. 
128. Makrides M, Neumann MA, Gibson RA. Effect of maternal docosahexaenoic acid (DHA) supplementation on breast milk composition. Eur J Clin Nutr 1996;50:352-7.

129. Lauritzen L, Jorgensen MH, Hansen HS, Michaelsen KF. Fluctuations in human milk long-chain PUFA levels in relation to dietary fish intake. Lipids 2002;37:237-44.

130. Jensen CL, Maude M, Anderson RE, Heird WC. Effect of docosahexaenoic acid supplementation of lactating women on the fatty acid composition of breast milk lipids and maternal and infant plasma phospholipids. Am J Clin Nutr 2000;71:S292-S299.

131. Aitchison JM, Dunkley WL, Canolty NL, Smith LM. Influence of diet on trans fatty acids in human milk. Am J Clin Nutr 1977;30:2006-15

132. Craig-Schmidt MC, Weete JD, Faircloth SA, Wickwire MA, Livant EJ. The effect of hydrogenated fat in the diet of nursing mothers on lipid composition and prostaglandin content of human milk. Am J Clin Nutr 1984;39:778-86.

133. Dobbing J, Sands J. Comparative aspects of the brain growth spurt. Early Hum Dev 1979;3:79-83.

134. Anderson JW, Johnstone BM, Remley DT. Breast-feeding and cognitive development: a meta-analysis. Am J Clin Nutr 1999;70:52535 .

135. Martinez M. Tissue levels of polyunsaturated fatty acids during early human development. J Pediatr 1992;120:S129-S138.

136. Jensen RG. Lipids in human milk. Lipids 1999;34:1243-71.

137. Uauy R, Dangour AD. Fat and fatty acid requirements and recommendations for infants of 0-2 years and children of 2-18 years. Ann Nutr Metab 2009;55:76-96.

138. Brenna JT, Varamini B, Jensen RG, Diersen-Schade DA, Boettcher JA, Arterburn LM. Docosahexaenoic and arachidonic acid concentrations in human breast milk worldwide. Am J Clin Nutr 2007;85:1457-64.

139. Makrides M, Neumann MA, Byard RW, Simmer K, Gibson RA. Fatty acid composition of brain, retina, and erythrocytes in breastand formula-fed infants. Am J Clin Nutr 1994;60:189-94.

140. Tanaka K, Kon N, Ohkawa N, Yoshikawa N, Shimizu T. Does breastfeeding in the neonatal period influence the cognitive function of very-low-birth-weight infants at 5 years of age? Brain Dev 2009;31:288-93.

141. Innis SM, Gilley J, Werker J. Are human milk long-chain polyunsaturated fatty acids related to visual and neural development in breast-fed term infants? J Pediatr 2001;139:532-8.

142. Jorgensen MH, Hernell O, Hughes E, Michaelsen KF. Is there a relation between docosahexaenoic acid concentration in mothers' milk and visual development in term infants? J Pediatr Gastroenterol Nutr 2001;32:293-6.

143. Jensen CL, Voigt RG, Prager TC, Zou YL, Fraley JK, Rozelle JC, Turcich MR, Llorente AM, Anderson RE, Heird WC. Effects of maternal docosahexaenoic acid intake on visual function and neurodevelopment in breastfed term infants. Am J Clin Nutr 2005;82:125-32.

144. Kankaanpaa P, Nurmela K, Erkkila A, Kalliomaki M, HolmbergMarttila D, Salminen S, Isolauri E. Polyunsaturated fatty acids in maternal diet, breast milk, and serum lipid fatty acids of infants in relation to atopy. Allergy: Allergy 2001;56:633-8.

145. Thijs C, Van HA, Poorterman I, Mordant A, Van Den BP. Essential fatty acids in breast milk of atopic mothers: Comparison with non-atopic mothers, and effect of borage oil supplementation. Eur J Clin Nutr 2000;54:234-8.

146. Lauritzen L, Kjaer TMR, Fruekilde M-B, Michaelsen KF, Frokiaer H. Fish oil supplementation of lactating mothers affects cytokine production in 2 1/2-year-old children. Lipids 2005;40:669-76.

147. Krauss-Etschmann S, Hartl D, Rzehak P, Heinrich J, Shadid R, Del CR-T, Campoy C, Pardillo S, Schendel DJ, Decsi T, Demmelmair H, Koletzko BV, Nutraceuticals for Healthier Life Study Group. Decreased cord blood IL-4, IL-13, and CCR4 and increased TGF-beta levels after fish oil supplementation of pregnant women. J Allergy Clin Immunol 2008;121:464-70.

148. Nwaru BI, Erkkola M, Ahonen S, Kaila M, Lumia M, Prasad M, Haapala AM, Kronberg-Kippila C, Veijola R, Ilonen J, Simell O, Knip M, Virtanen SM. Maternal diet during lactation and allergic sensitization in the offspring at age of 5. Pediatr Allergy
Immunol 2011; Epub ahead of print: (doi) 10.1111/j.13993038.2010.01114.x.

149. Damsgaard CT, Lauritzen L, Kjaer TMR, Holm PMI, Fruekilde M-B, Michaelsen KF, Frokiaer H. Fish oil supplementation modulates immune function in healthy infants. J Nutr 2007;137:1031-6.

150. Nafstad P, Nystad W, Magnus P, Jaakkola JJ. Asthma and allergic rhinitis at 4 years of age in relation to fish consumption in infancy. J Asthma 2003;40:343-8.

151. Kull I, Bergstrom A, Lilja G, Pershagen G, Wickman M. Fish consumption during the first year of life and development of allergic diseases during childhood. Allergy 2006;61:1009-15.

152. Marks GB, Mihrshahi S, Kemp AS, Tovey ER, Webb K, Almqvist C, Ampon RD, Crisafulli D, Belousova EG, Mellis CM, Peat JK, Leeder SR. Prevention of asthma during the first 5 years of life: A randomized controlled trial. J Allergy Clin Immunol 2006;118:5361.

153. Birch EE, Garfield S, Castaneda Y, Hughbanks-Wheaton D, Uauy R, Hoffman D. Visual acuity and cognitive outcomes at 4 years of age in a double-blind, randomized trial of long-chain polyunsaturated fatty acid-supplemented infant formula. Early Hum Dev 2007;83:279-84.

154. Birch EE, Carlson SE, Hoffman DR, Fitzgerald-Gustafson KM, Fu VL, Drover JR, Castaneda YS, Minns L, Wheaton DK, Mundy D, Marunycz J, Diersen-Schade DA. The DIAMOND (DHA Intake And Measurement Of Neural Development) Study: a double-masked, randomized controlled clinical trial of the maturation of infant visual acuity as a function of the dietary level of docosahexaenoic acid. Am J Clin Nutr 2010;91:848-59.

155. Bouwstra H, Dijck-Brouwer J, Decsi T, Boehm G, Boersma ER, Muskiet FA, Hadders-Algra M. Neurologic condition of healthy term infants at 18 months: positive association with venous umbilical DHA status and negative association with umbilical transfatty acids. Pediatr Res 2006;60:334-9.

156. Eilander A, Hundscheid DC, Osendarp SJ, Transler C, Zock PL. Effects of n-3 long chain polyunsaturated fatty acid supplementation on visual and cognitive development throughout childhood: a review of human studies. Prostaglandins Leukot Essent Fatty Acids 2007;76:189-203.

157. Transler C, Eilander A, Mitchell S, van de Meer N. The impact of polyunsaturated fatty acids in reducing child attention deficit and hyperactivity disorders. J Atten Disord 2010;14:232-46.

158. Vecka M, Richterova B, Zak A, Tvrzicka E, Sramkova P, Stankova B, Klimcakova E, Stich V. Changes in serum and adipose tissue fatty acid composition after low calorie diet with respect to dietary fat content in obese. Cas Les Cesk 2006;145:464-9.

159. Hlavaty P, Kunesova M, Gojova M, Tvrzicka E, Vecka M, Roubal P, Hill M, Hlavata K, Kalouskova P, Hainer V, Zak A, Drbohlav J. Change in fatty acid composition of serum lipids in obese females after short-term weight-reducing regimen with the addition of $n-3$ long chain polyunsaturated fatty acids in comparison to controls. Physiol Res 2008;57:S57-S65.

160. Kunesova M, Braunerova R, Hlavaty P, Trrzicka E, Stankova B, Skrha J, Hilgertova J, Hill M, Kopecky J, Wagenknecht M, Hainer V, Matoulek M, Parizkova J, Zak A, Svacina S. The influence of n-3 polyunsaturated fatty acids and very low calorie diet during a short-term weight reducing regimen on weight loss and serum fatty acid composition in severely obese women. Physiol Res 2006;55:63-72.

161. Asp ML, Collene AL, Norris LE, Cole RM, Stout MB, Tang SY, Hsu JC, Belury MA. Time-dependent effects of safflower oil to improve glycemia, inflammation and blood lipids in obese, post-menopausal women with type 2 diabetes: A randomized, double-masked, crossover study. Clin Nutr 2011; Epub ahead of print: (doi) 10.1016/j.clnu.2011.01.001.

162. Teng KT, Nagapan G, Cheng HM, Nesaretnam K. Palm Olein and Olive Oil Cause a Higher Increase in Postprandial Lipemia Compared with Lard but Had No Effect on Plasma Glucose, Insulin and Adipocytokines. Lipids 2011; Epub ahead of print: (doi) 10.1007/s11745-010-3516-y.

163. Teng KT, Voon PT, Cheng HM, Nesaretnam K. Effects of partially hydrogenated, semi-saturated, and high oleate vegetable oils on inflammatory markers and lipids. Lipids 2010;45:385-92. 
164. Gillingham LG, Gustafson JA, Han SY, Jassal DS, Jones PJ. Higholeic rapeseed (canola) and flaxseed oils modulate serum lipids and inflammatory biomarkers in hypercholesterolaemic subjects. Br J Nutr 2011;105:417-27.

165. Kwak JH, Paik JK, Kim OY, Jang Y, Lee SH, Ordovas JM, Lee JH. FADS gene polymorphisms in Koreans: association with omega 6 polyunsaturated fatty acids in serum phospholipids, lipid peroxides, and coronary artery disease. Atherosclerosis 2011;214:94-100.

166. Lu Y, Feskens EJ, Dolle ME, Imholz S, Verschuren WM, Muller M, Boer JM. Dietary n-3 and n-6 polyunsaturated fatty acid intake interacts with FADS1 genetic variation to affect total and HDLcholesterol concentrations in the Doetinchem Cohort Study. Am J Clin Nutr 2010;92:258-65.

167. Martinelli N, Girelli D, Malerba G, Guarini P, Illig T, Trabetti E, Sandri M, Friso S, Pizzolo F, Schaeffer L, Heinrich J, Pignatti PF, Corrocher R, Olivieri O. FADS genotypes and desaturase activity estimated by the ratio of arachidonic acid to linoleic acid are associated with inflammation and coronary artery disease. Am J Clin Nutr 2008;88:941-9.

168. Malerba G, Schaeffer L, Xumerle L, Klopp N, Trabetti E, Biscuola M, Cavallari U, Galavotti R, Martinelli N, Guarini P, Girelli D, Olivieri O, Corrocher R, Heinrich J, Pignatti PF, Illig T. SNPs of the FADS gene cluster are associated with polyunsaturated fatty acids in a cohort of patients with cardiovascular disease. Lipids 2008;43:289-99.

169. Schaeffer L, Gohlke H, Muller M, Heid IM, Palmer LJ, Kompauer I, Demmelmair H, Illig T, Koletzko B, Heinrich J. Common genetic variants of the FADS1 FADS2 gene cluster and their reconstructed haplotypes are associated with the fatty acid composition in phospholipids. Hum Mol Genet 2006;15:1745-56.

170. Park JY, Paik JK, Kim OY, Chae JS, Jang Y, Lee JH. Interactions between the APOA5 -1131T $>C$ and the FEN1 10154G $>$ T polymorphisms on omega 6 polyunsaturated fatty acids in serum phospholipids and coronary artery disease. J Lipid Res 2010;51:3281-8.

171. Simopoulos AP. Genetic variants in the metabolism of omega- 6 and omega-3 fatty acids: their role in the determination of nutritional requirements and chronic disease risk. Exp Biol Med (Maywood ) 2010;235:785-95.

172. Glaser C, Heinrich J, Koletzko B. Role of FADS1 and FADS2 polymorphisms in polyunsaturated fatty acid metabolism. Metabolism 2010;59:993-9.

173. Zak A, Vecka M, Tvrzicka E, Hruby M, Novak F, Papezova H, Lubanda H, Vesela L, Stankova B. Composition of plasma fatty acids and non-cholesterol sterols in anorexia nervosa. Physiol Res 2005;54:443-51.

174. Zak A, Jachymova M, Tvrzicka E, Vecka M, Duffkova L, Zeman M, Slaby A, Stankova B. The influence of polymorphism of $-493 \mathrm{G} / \mathrm{T}$ MTP gene promoter and metabolic syndrome on lipids, fatty acids and oxidative stress. J Nutr Biochem 2008;19:634-41.

175. Zeman M, Vecka M, Jachymova M, Jirak R, Tvrzicka E, Stankova B, Zak A. Fatty acid CoA ligase-4 gene polymorphism influences fatty acid metabolism in metabolic syndrome, but not in depression. Tohoku J Exp Med 2009;217:287-93.

176. Brenner RR. Factors influencing Fatty Acid Chain Elongation and Desaturation. In: Vergroesen AJ, Crawford M, editors. The role of fats in human nutrition. London: Academic Press; 1989. p. 45-79.

177. Burr GO, Burr MM. Nutrition classics from The Journal of Biological Chemistry 82:345-67, 1929. A new deficiency disease produced by the rigid exclusion of fat from the diet. Nutr Rev 1973;31:248-9.

178. Crawford MA, Doyle W, Williams G, Drury PJ. The role of fats and EFAs for energy and cell structures in the growth of fetus and neonate. In: Vergroesen AJ, Crawford M, editors. The role of fats in human nutrition. London: Academic Press; 1989. p. 82-116.

179. Kinsella JE, Broughton KS, Whelan JW. Dietary unsaturated fatty acids: interactions and possible needs in relation to eicosanoid synthesis. J Nutr Biochem 1990;1:123-41.

180. Seo T, Blaner WS, Deckelbaum RJ. Omega-3 fatty acids: molecular approaches to optimal biological outcomes. Curr Opin Lipidol 2005; $16: 11-8$
181. Mead JF. The metabolism of polyunsaturated fatty acids. In: Holman RT, editor. Progress in the Chemistry of Fats and other Lipids. Oxford: Pergamon Press; 1971. p. 161-189.

182. Mead JF. The metabolism of the essential fatty acids. Am J Clin Nutr 1958; 6:656-61.

183. Dyerberg J. Linolenate-derived polyunsaturated fatty acids and prevention of atherosclerosis. Nutr Rev 1986;44:125-34.

184. Feskens EJ, Virtanen SM, Rasanen L, Tuomilehto J, Stengard J, Pekkanen J, Nissinen A, Kromhout D. Dietary factors determining diabetes and impaired glucose tolerance. A 20-year follow-up of the Finnish and Dutch cohorts of the Seven Countries Study. Diabetes Care 1995;18:1104-12.

185. Holman RT, Johnson SB, Hatch TF. A case of human linolenic acid deficiency involving neurological abnormalities. Am J Clin Nutr 1982;35:617-23.

186. Gadek JE, DeMichele SJ, Karlstad MD, Pacht ER, Donahoe M, Albertson TE, Van HC, Wennberg AK, Nelson JL, Noursalehi M. Effect of enteral feeding with eicosapentaenoic acid, gammalinolenic acid, and antioxidants in patients with acute respiratory distress syndrome. Enteral Nutrition in ARDS Study Group. Crit Care Med 1999;27:1409-20.

187. Martinez M. The fundamentals and practice of docosahexaenoic acid therapy in peroxisomal disorders. Current Opinion in Clinical Nutrition \& Metabolic Care 2000;3:101-8.

188. Oberkofler H, Liu YM, Esterbauer H, Hell E, Krempler F, Patsch W. Uncoupling protein-2 gene: reduced mRNA expression in intraperitoneal adipose tissue of obese humans. Diabetologia 1998;41:940-6.

189. Zak A, Tvrzicka E, Vecka M, Jachymova M, Duffkova L, Stankova B, Vavrova L, Kodydkova J, Zeman M. Severity of metabolic syndrome unfavorably influences oxidative stress and fatty acid metabolism in men. Tohoku J Exp Med 2007;212:359-71.

190. Astrup A, Dyerberg J, Elwood P, Hermansen K, Hu FB, Jakobsen MU, Kok FJ, Krauss RM, Lecerf JM, Legrand P, Nestel P, Riserus U, Sanders T, Sinclair A, Stender S, Tholstrup T, Willett $\mathrm{W}$. The role of reducing intakes of saturated fat in the prevention of cardiovascular disease: where does the evidence stand in 2010? Am J Clin Nutr 2011; Epub ahead of print: (doi) 10.3945/ ajcn.110.004622.

191. Bysted A, Holmer G, Lund P, Sandstrom B, Tholstrup T. Effect of dietary fatty acids on the postprandial fatty acid composition of triacylglycerol-rich lipoproteins in healthy male subjects. Eur J Clin Nutr 2005;59:24-34.

192. Tholstrup T, Samman S. Postprandial lipoprotein(a) is affected differently by specific individual dietary fatty acids in healthy young men. J Nutr 2004;134:2550-5.

193. Tholstrup T, Teng KT, Raff M. Dietary Cocoa Butter or Refined Olive Oil Does Not Alter Postprandial hsCRP and IL-6 Concentrations in Healthy Women. Lipids 2011; Epub ahead of print: (doi) 10.1007/s11745-011-3526-4.

194. Sanders TA, Oakley FR, Cooper JA, Miller GJ. Influence of a stearic acid-rich structured triacylglycerol on postprandial lipemia, factor VII concentrations, and fibrinolytic activity in healthy subjects. Am J Clin Nutr 2001;73:715-21.

195. Tholstrup T, Vessby B, Sandstrom B. Difference in effect of myristic and stearic acid on plasma HDL cholesterol within $24 \mathrm{~h}$ in young men. Eur J Clin Nutr 2003;57:735-42.

196. Mozaffarian D, Aro A, Willett WC. Health effects of trans-fatty acids: experimental and observational evidence. Eur J Clin Nutr 2009;63:5S-21S.

197. Tardy AL, Morio B, Chardigny JM, Malpuech-Brugere C. Ruminant and industrial sources of trans-fat and cardiovascular and diabetic diseases. Nutr Res Rev 2011; Epub ahead of print: (doi) 10.1017/S0954422411000011.

198. Adhikari P, Shin JA, Lee JH, Hu JN, Zhu XM, Akoh CC, Lee KT. Production of trans-free margarine stock by enzymatic interesterification of rice bran oil, palm stearin and coconut oil. J Sci Food Agric 2010;90:703-11.

199. Gillingham LG, Harris-Janz S, Jones PJ. Dietary Monounsaturated Fatty Acids Are Protective Against Metabolic Syndrome and Cardiovascular Disease Risk Factors. Lipids 2011; Epub ahead of print: (doi) 10.1007/s11745-010-3524-y. 
200. Marchioli R, Barzi F, Bomba E, Chieffo C, Di GD, Di MR, Franzosi MG, Geraci E, Levantesi G, Maggioni AP, Mantini L, Marfisi RM, Mastrogiuseppe G, Mininni N, Nicolosi GL, Santini M, Schweiger C, Tavazzi L, Tognoni G, Tucci C, Valagussa F. Early protection against sudden death by $n-3$ polyunsaturated fatty acids after myocardial infarction: time-course analysis of the results of the Gruppo Italiano per lo Studio della Sopravvivenza nell'Infarto Miocardico (GISSI)-Prevenzione. Circulation 2002;105:1897-903.

201. Ramsden CE, Hibbeln JR, Majchrzak SF, Davis JM. n-6 fatty acid-specific and mixed polyunsaturate dietary interventions have different effects on CHD risk: a meta-analysis of randomised controlled trials. Br J Nutr 2010;104:1586-600.

202. Singh RB, Dubnov G, Niaz MA, Ghosh S, Singh R, Rastogi SS, Manor O, Pella D, Berry EM. Effect of an Indo-Mediterranean diet on progression of coronary artery disease in high risk patients (Indo-Mediterranean Diet Heart Study): a randomised singleblind trial. Lancet 2002;360:1455-61.

203. Kromann N, Green A. Epidemiological studies in the Upernavik district, Greenland. Incidence of some chronic diseases 19501974. Acta Med Scand 1980;208:401-6.

204. Bang HO, Dyerberg J, Sinclair HM. The composition of the Eskimo food in north western Greenland. Am J Clin Nutr 1980;33:2657-61.

205. Tavazzi L, Maggioni AP, Marchioli R, Barlera S, Franzosi MG, Latini R, Lucci D, Nicolosi GL, Porcu M, Tognoni G. Effect of $n-3$ polyunsaturated fatty acids in patients with chronic heart failure (the GISSI-HF trial): a randomised, double-blind, placebocontrolled trial. Lancet 2008;372:1223-30.

206. Thies F, Garry JM, Yaqoob P, Rerkasem K, Williams J, Shearman CP, Gallagher PJ, Calder PC, Grimble RF. Association of n-3 polyunsaturated fatty acids with stability of atherosclerotic plaques: a randomised controlled trial. Lancet 2003; 361:477-85.

207. Amani R, Noorizadeh M, Rahmanian S, Afzali N, Haghighizadeh MH. Nutritional related cardiovascular risk factors in patients with coronary artery disease in Iran: a case-control study. Nutr J 2010;9:70.

208. Iso H. Lifestyle and Cardiovascular Disease in Japan. J Atheroscler Thromb 2011; Epub ahead of print: (doi) JST. JSTAGE/jat/6866

209. Serhan CN, Gotlinger K, Hong S, Arita M. Resolvins, docosatrienes, and neuroprotectins, novel omega-3-derived mediators, and their aspirin-triggered endogenous epimers: an overview of their protective roles in catabasis. Prostaglandins Other Lipid Mediat 2004;73:155-72.

210. Yaqoob P, Calder PC. Fatty acids and immune function: new insights into mechanisms. Br J Nutr 2007;98:S41-S45.

211. Calder PC, Yaqoob P. Omega-3 (n-3) fatty acids, cardiovascular disease and stability of atherosclerotic plaques. Cell Mol Biol 2010;56:28-37.

212. Skulas-Ray AC, West SG, Davidson MH, Kris-Etherton PM Omega-3 fatty acid concentrates in the treatment of moderate hypertriglyceridemia. Expert Opin Pharmacother 2008;9:1237-48

213. Musa-Veloso K, Binns MA, Kocenas AC, Poon T, Elliot JA, Rice H, Oppedal-Olsen H, Lloyd H, Lemke S. Long-chain omega-3 fatty acids eicosapentaenoic acid and docosahexaenoic acid dose-dependently reduce fasting serum triglycerides. Nutr Rev 2010;68:155-67.

214. Zak A, Hrabak P, Zeman M. Treatment of severe hypertriglyceridemia with a combination of $\mathrm{n}-3$ fatty acids and bezafibrate. In: Gotto AM, Mancini M, Richter WO, Schwandt P, editors. Treatment of severe dylipoproteinemia in the prevention of coronary heart disease - 3rd Int Symp Munich 1990. Basel Karger;1992. p. 240-4.

215. Zeman M, Zak A, Vecka M, Tvrzicka E, Pisarikova A, Stankova B. N-3 fatty acid supplementation decreases plasma homocysteine in diabetic dyslipidemia treated with statin-fibrate combination. J Nut Biochem 2006;17:379-84.

216. de Lorgeril M, Salen P, Guiraud A, Zeghichi S, Boucher F, de Leiris J. Lipid-lowering drugs and essential omega-6 and omega-3 fatty acids in patients with coronary heart disease. Nutr Metab Cardiovasc Dis 2005;15:36-41.
217. Studer M, Briel M, Leimenstoll B, Glass TR, Bucher HC. Effect of different antilipidemic agents and diets on mortality: a systematic review. Arch Intern Med 2005;165:725-30.

218. Manco M, Calvani M, Mingrone G. Effects of dietary fatty acids on insulin sensitivity and secretion. Diabetes Obes Metab 2004;6:402-13.

219. Stein DT, Stevenson BE, Chester MW, Basit M, Daniels MB, Turley SD, McGarry JD. The insulinotropic potency of fatty acids is influenced profoundly by their chain length and degree of saturation. J Clin Invest 1997;100:398-403.

220. Montecucco F, Steffens S, Mach F. Insulin resistance: a proinflammatory state mediated by lipid-induced signaling dysfunction and involved in atherosclerotic plaque instability. Mediators Inflamm 2008; (doi) 10.1155/2008/767623.

221. Lopez S, Bermudez B, Pacheco YM, Villar J, Abia R, Muriana FJ. Distinctive postprandial modulation of beta cell function and insulin sensitivity by dietary fats: monounsaturated compared with saturated fatty acids. Am J Clin Nutr 2008;88:638-44.

222. Rojo-Martinez G, Esteva I, Ruiz de Adana MS, Garcia-Almeida JM, Tinahones F, Cardona F, Morcillo S, Garcia-Escobar E, Garcia-Fuentes E, Soriguer F. Dietary fatty acids and insulin secretion: a population-based study. Eur J Clin Nutr 2006;60:1195200.

223. Cerf ME. High fat diet modulation of glucose sensing in the betacell. Med Sci Monit 2007;13:RA12-RA17.

224. Martin de Santa OL, Sanchez Muniz FJ, Vaquero MP. N-3 fatty acids in glucose metabolism and insulin sensitivity. Nutr Hosp 2009;24:113-27.

225. Navas-Carretero S, Perez-Granados AM, Schoppen S, Vaquero MP. An oily fish diet increases insulin sensitivity compared to a red meat diet in young iron-deficient women. $\mathrm{Br} \mathrm{J}$ Nutr 2009;102:546-53.

226. Mori TA, Bao DQ, Burke V, Puddey IB, Watts GF, Beilin LJ. Dietary fish as a major component of a weight-loss diet: effect on serum lipids, glucose, and insulin metabolism in overweight hypertensive subjects. Am J Clin Nutr 1999;70:817-25.

227. Browning LM, Krebs JD, Moore CS, Mishra GD, O'Connell MA, Jebb SA. The impact of long chain n-3 polyunsaturated fatty acid supplementation on inflammation, insulin sensitivity and CVD risk in a group of overweight women with an inflammatory phenotype. Diabetes Obes Metab 2007;9:70-80.

228. Carroll KK. Dietary fat and cancer: specific action or caloric effect? J Nutr 1986;116:1130-2.

229. Costa I, Moral R, Solanas M, Andreu FJ, Ruiz de Villa MC, Escrich E. High corn oil and extra virgin olive oil diets and experimental mammary carcinogenesis: clinicopathological and immunohistochemical p21Ha-Ras expression study. Virchows Arch 2011;458:141-51.

230. Weisburger JH. Dietary fat and risk of chronic disease: mechanistic insights from experimental studies. J Am Diet Assoc 1997;97:16S-23S.

231. Stehr SN, Heller AR. Omega-3 fatty acid effects on biochemical indices following cancer surgery. Clin Chim Acta 2006;373:1-8.

232. Berquin IM, Edwards IJ, Chen YQ. Multi-targeted therapy of cancer by omega-3 fatty acids. Cancer Lett 2008;269:363-77.

233. Kalapothaki V, Tzonou A, Hsieh CC, Karakatsani A, Trichopoulou A, Toupadaki N, Trichopoulos D. Nutrient intake and cancer of the pancreas: a case-control study in Athens, Greece. Cancer Causes Control 1993;4:383-9.

234. Zhang J, Dhakal IB, Gross MD, Lang NP, Kadlubar FF, Harnack LJ, Anderson KE. Physical activity, diet, and pancreatic cancer: a population-based, case-control study in Minnesota. Nutr Cancer 2009:61:457-65.

235. Ghadirian P, Simard A, Baillargeon J, Maisonneuve P, Boyle P. Nutritional factors and pancreatic cancer in the francophone community in Montreal, Canada. Int J Cancer 1991;47:1-6.

236. Brown TT, Zelnik DL, Dobs AS. Fish oil supplementation in the treatment of cachexia in pancreatic cancer patients. Int $\mathbf{J}$ Gastrointest Cancer 2003;34:143-50.

237. Gong Z, Holly EA, Wang F, Chan JM, Bracci PM. Intake of fatty acids and antioxidants and pancreatic cancer in a large popula- 
tion-based case-control study in the San Francisco Bay Area. Int J Cancer 2010;127:1893-904.

238. Boutros C, Somasundar P, Razzak A, Helton S, Espat NJ. Omega-3 fatty acids: investigations from cytokine regulation to pancreatic cancer gene suppression. Arch Surg 2010;145:515-20.

239. Kilian M, Gregor JI, Heukamp I, Wagner C, Walz MK, Schimke I, Kristiansen G, Wenger FA. Early inhibition of prostaglandin synthesis by n-3 fatty acids determinates histologic severity of necrotizing pancreatitis. Pancreas 2009;38:436-41.

240. Funahashi H, Satake M, Hasan S, Sawai H, Newman RA, Reber HA, Hines OJ, Eibl G. Opposing effects of n- 6 and n-3 polyunsaturated fatty acids on pancreatic cancer growth. Pancreas 2008;36:353-62.

241. Heller AR, Rossel T, Gottschlich B, Tiebel O, Menschikowski M, Litz RJ, Zimmermann T, Koch T. Omega-3 fatty acids improve liver and pancreas function in postoperative cancer patients. Int J Cancer 2004;111:611-6.

242. Clarke SD. The multi-dimensional regulation of gene expression by fatty acids: polyunsaturated fats as nutrient sensors. Curr Opin Lipidol 2004;15:13-8.

243. Kenler AS, Swails WS, Driscoll DF, DeMichele SJ, Daley B, Babineau TJ, Peterson MB, Bistrian BR. Early enteral feeding in postsurgical cancer patients. Fish oil structured lipid-based polymeric formula versus a standard polymeric formula. Ann Surg 1996;223:316-33

244. Sala-Vila A, Barbosa VM, Calder PC. Olive oil in parenteral nutrition. Curr Opin Clin Nutr Metab Care 2007;10:165-74.

245. Calder PC, Jensen GL, Koletzko BV, Singer P, Wanten GJ. Lipid emulsions in parenteral nutrition of intensive care patients: current thinking and future directions. Intensive Care Med 2010;36:735-49.

246. Mayer K, Seeger W. Fish oil-containing lipid emulsions in patients with sepsis. Crit Care 2010;14:128.

247. Novak F, Borovska J, Vecka M, Vavrova L, Kodydkova J, Mrackova M, Novak F, Sr., Novakova O, Zak A. Alterations in fatty acid composition of plasma and erythrocyte lipids in critically ill patients during sepsis. Cas Lek Cesk 2010;149:324-31.

248. Barbosa VM, Miles EA, Calhau C, Lafuente E, Calder PC. Effects of a fish oil containing lipid emulsion on plasma phospholipid fatty acids, inflammatory markers, and clinical outcomes in septic patients: a randomized, controlled clinical trial. Crit Care 2010;14:R5.

249. Ferdinandusse S, Denis S, Mooijer PA, Zhang Z, Reddy JK, Spector AA, Wanders RJ. Identification of the peroxisomal betaoxidation enzymes involved in the biosynthesis of docosahexaenoic acid. J Lipid Res 2001;42:1987-95.

250. Colomer R, Moreno-Nogueira JM, Garcia-Luna PP, Garcia-Peris P, Garcia-de-Lorenzo A, Zarazaga A, Quecedo L, del LJ, Usan L, Casimiro C. N-3 fatty acids, cancer and cachexia: a systematic review of the literature. Br J Nutr 2007;97:823-31.

251. Smith HJ, Greenberg NA, Tisdale MJ. Effect of eicosapentaenoic acid, protein and amino acids on protein synthesis and degradation in skeletal muscle of cachectic mice. Br J Cancer 2004;91:408-12.

252. Adam O, Beringer C, Kless T, Lemmen C, Adam A, Wiseman M, Adam P, Klimmek R, Forth W. Anti-inflammatory effects of a low arachidonic acid diet and fish oil in patients with rheumatoid arthritis. Rheumatol Int 2003;23:27-36.
253. Volker D, Fitzgerald P, Major G, Garg M. Efficacy of fish oil concentrate in the treatment of rheumatoid arthritis. J Rheumatol 2000; 27:2343-6.

254. Kremer JM, Lawrence DA, Petrillo GF, Litts LL, Mullaly PM, Rynes RI, Stocker RP, Parhami N, Greenstein NS, Fuchs BR. Effects of high-dose fish oil on rheumatoid arthritis after stopping nonsteroidal antiinflammatory drugs. Clinical and immune correlates. Arthritis Rheum 1995;38:1107-14.

255. Aslan A, Triadafilopoulos G. Fish oil fatty acid supplementation in active ulcerative colitis: a double-blind, placebo-controlled, crossover study. Am J Gastroenterol 1992;87:432-7.

256. Lorenz R, Weber PC, Szimnau P, Heldwein W, Strasser T, Loeschke K. Supplementation with n-3 fatty acids from fish oil in chronic inflammatory bowel disease-a randomized, placebo-controlled, double-blind cross-over trial. J Intern Med 1989;731:S225-S232.

257. Nordvik I, Myhr KM, Nyland H, Bjerve KS. Effect of dietary advice and $\mathrm{n}-3$ supplementation in newly diagnosed MS patients. Acta Neurol Scand 2000; 102:143-9.

258. Duffy EM, Meenagh GK, McMillan SA, Strain JJ, Hannigan $\mathrm{BM}$, Bell AL. The clinical effect of dietary supplementation with omega-3 fish oils and/or copper in systemic lupus erythematosus. J Rheumatol 2004;31:1551-61.

259. Ilowite NT, Copperman N, Leicht T, Kwong T, Jacobson MS. Effects of dietary modification and fish oil supplementation on dyslipoproteinemia in pediatric systemic lupus erythematosus. J Rheumatol 1995;22:1347-51.

260. Black PN, Sharpe S. Dietary fat and asthma: is there a connection? Eur Respir J 1997;10:6-12.

261. Hodge L, Peat JK, Salome C. Increased consumption of polyunsaturated oils may be a cause of increased prevalence of childhood asthma. Aust N Z J Med1994;24:727.

262. Miles EA, Aston L, Calder PC. In vitro effects of eicosanoids derived from different 20-carbon fatty acids on $\mathrm{T}$ helper type 1 and $\mathrm{T}$ helper type 2 cytokine production in human whole-blood cultures. Clin Exp Allergy 2003;33:624-32.

263. Roper RL, Phipps RP. Prostaglandin E2 regulation of the immune response. Adv Prostaglandin Thromboxane Leukot Res 1994;22:101-11.

264. Arm JP, Horton CE, Mencia-Huerta JM, House F, Eiser NM, Clark TJ, Spur BW, Lee TH. Effect of dietary supplementation with fish oil lipids on mild asthma. Thorax 1988;43:84-92.

265. Kirsch CM, Payan DG, Wong MY, Dohlman JG, Blake VA, Petri MA, Offenberger J, Goetzl EJ, Gold WM. Effect of eicosapentaenoic acid in asthma. Clin Allergy 1988;18:177-87.

266. Payan DG, Wong MY, Chernov-Rogan T, Valone FH, Pickett WC, Blake VA, Gold WM, Goetzl EJ. Alterations in human leukocyte function induced by ingestion of eicosapentaenoic acid. J Clin Immunol1986;6:402-10.

267. Schachter HM, Reisman J, Tran K, Dales B, Kourad K, Barnes D, Sampson M, Morrison A, Gaboury I, Blackman J. Health effects of omega-3 fatty acids on asthma. Evid RepTechnol Assess 2004:91:1-7.

268. Woods RK, Thien FC, Abramson MJ. Dietary marine fatty acids (fish oil) for asthma in adults and children. Cochrane Database Syst Rev 2002;3:CD001283. 